Engineering and Computational Mechanics Volume 170 Issue EM1

Hydraulic jumps and breaking bores: modelling and analysis

Wang, Leng and Chanson

ice | proceedings
Proceedings of the Institution of Civil Engineers

Engineering and Computational Mechanics 170 March 2017 Issue EM1 Pages 25-42 http://dx.doi.org/10.1680/jencm.16.00025

\title{
Hydraulic jumps and breaking bores: modelling and analysis
}

Hang Wang PhD

Research Fellow, School of Civil Engineering, The University of Queensland, Brisbane, Australia (Orcid:0000-0002-3542-8416)

Xinqian Leng BEng

Research student, School of Civil Engineering, The University of

Queensland, Brisbane, Australia (Orcid:0000-0001-8472-7925)
Hubert Chanson ME, PhD (Cant.), DEng (QId), Eurlng, MIEAust Professor, School of Civil Engineering, The University of Queensland, Brisbane, Australia (corresponding author: h.chanson@uq.edu.au) (Orcid:0000-0002-2016-9650)

In open channel flows, the transition from a rapid to fluvial flow motion is called a hydraulic jump. A related flow motion is a compression wave in a channel, such as a tidal bore or surge. A key feature of hydraulic jumps and breaking bores is the rapid spatial and temporal deformations of the free surface of the roller region, in response to the interactions between entrained air bubbles and turbulent structures. The flow structure in the roller remains a great research challenge due to large quantities of entrained air, bubble-turbulence interactions and the coupling between turbulent properties and free-surface deformations. Breaking bores and hydraulic jumps with a marked roller present a number of similar features that are discussed herein. Recent results have shown that the roller is a highly unsteady turbulent region, with both the roller toe and free surface constantly fluctuating with time and space, although the roller shape is quasi-two-dimensional on average. Downstream of the roller toe, air bubbles and vorticity are diffused in the shear zone at different rates. The double diffusive convection process leads to a complex interplay between instantaneous free-surface deformations, velocity fluctuations and interfacial processes including breakup and coalescence.

\begin{tabular}{l} 
Notation \\
$D_{\mathrm{ab}}$ \\
$d$ \\
$d_{1}$ \\
$d_{2}$ \\
$F$ \\
$\mathrm{Fr}_{1}$ \\
$\mathrm{~g}$ \\
$k_{\mathrm{s}}$ \\
$L_{\mathrm{r}}$ \\
$N_{\mathrm{c}}$ \\
$P$ \\
$Q$ \\
\hline$U$ \\
$V$ \\
$v^{\prime}$ \\
$v_{1}^{\prime}$ \\
$W$ \\
$X$ \\
$X$ toe \\
$x, y$ and $z$ \\
\end{tabular}

void fraction

characteristic bubble size

water depth

inflow depth

tailwater/conjugate depth

bubble count rate

inflow Froude number

acceleration of gravity

equivalent sand roughness height

jump roller length over which the water level increases monotonically from $d_{1}$ to $d_{2}$ number of bubble clusters per second

pressure

water discharge

transverse-averaged bore celerity

mean velocity

velocity fluctuation

inflow velocity fluctuations

channel width

transverse-averaged roller toe position at time $t$ mean jump toe position

$x, y$ and $z$ longitudinal, transverse and vertical coordinates, respectively

$\begin{array}{ll}Z_{C \min } & \begin{array}{l}\text { vertical position of local minimum void fraction at } \\ \text { the boundary between turbulent shear flow and } \\ \text { free-surface regions }\end{array} \\ \delta_{1} & \text { inflow boundary layer thickness } \\ \mu & \text { water dynamic viscosity } \\ \rho & \text { water density } \\ \sigma & \text { surface tension between air and water }\end{array}$

\section{Introduction}

In free-surface flows, the transition from a rapid to fluvial flow motion is called a hydraulic jump. Figure 1 presents a number of environmental applications. A hydraulic jump is characterised by large-scale turbulence, some air bubble entrainment and a substantial rate of energy dissipation (Bakhmeteff, 1932; Chanson, 2009a; Hager, 1992). For a stationary hydraulic jump in a smooth, horizontal, rectangular channel, the power dissipated in the jump equals

1. $\frac{1}{16} \rho g Q d_{1} \frac{\left(\sqrt{1+8 \mathrm{Fr}_{1}^{2}}-3\right)^{3}}{\sqrt{1+8 \mathrm{Fr}_{1}^{2}}-1}$ 


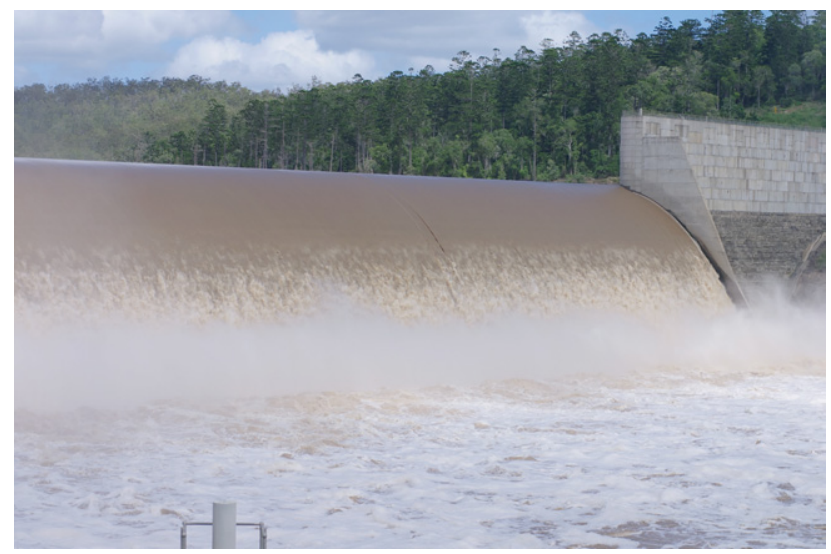

(a)
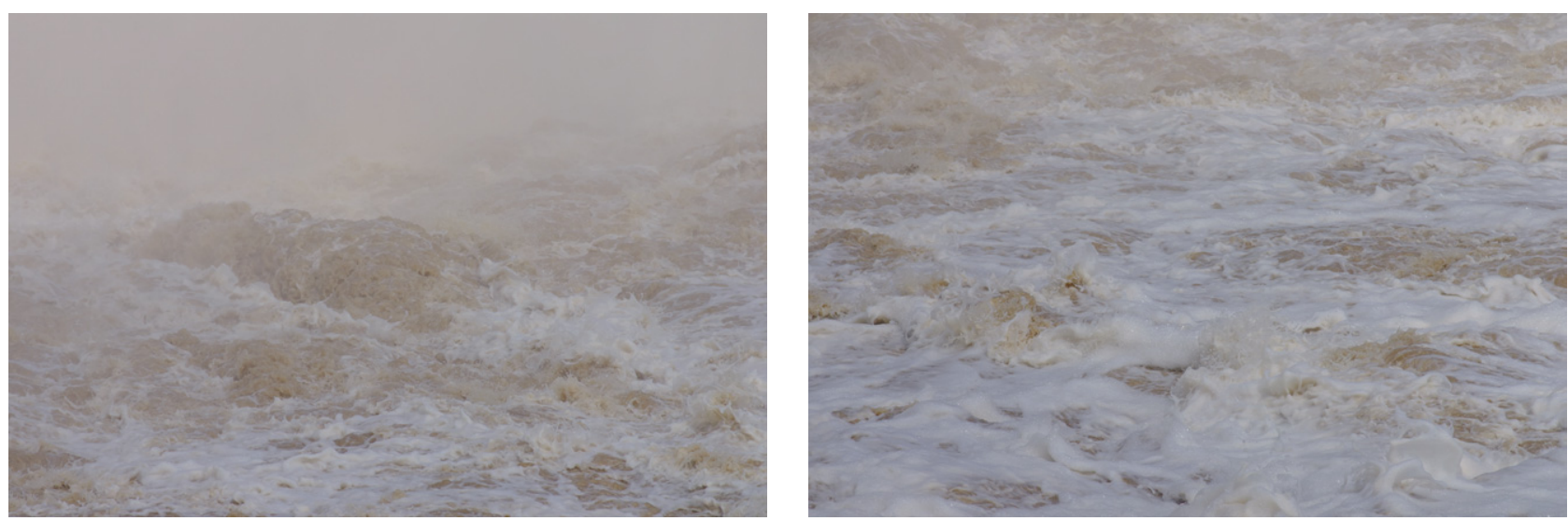

(b)

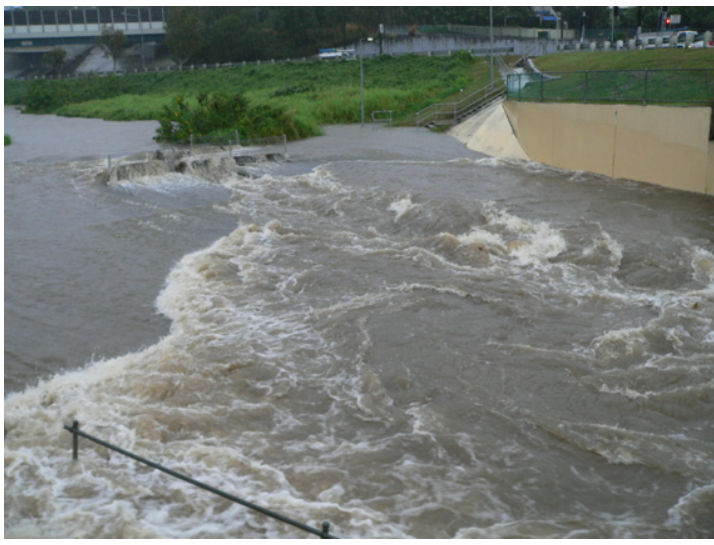

(c)

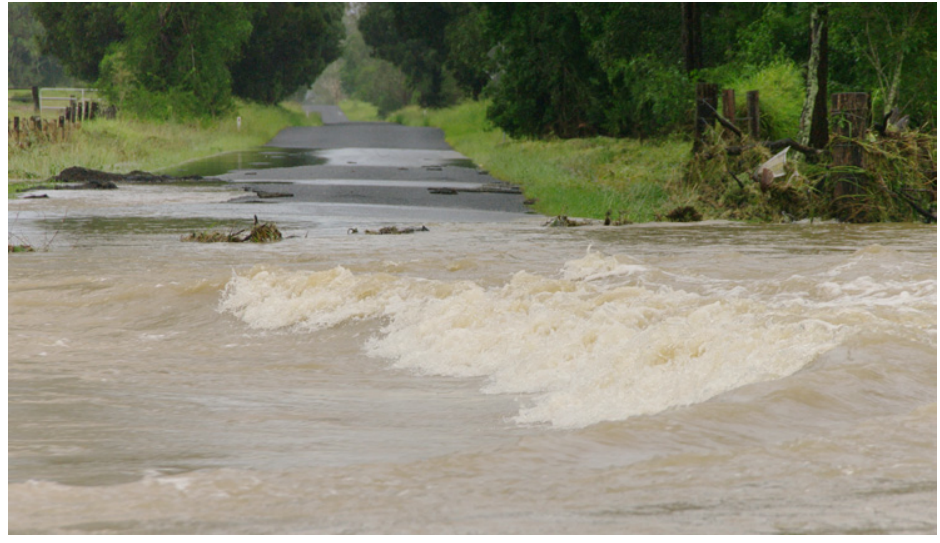

(d)
Figure 1. Hydraulic jump applications: (a) hydraulic jump at the toe of Paradise dam spillway on the Burnett River (Australia) on 5 March 2013: $Q=2300 \mathrm{~m}^{3} / \mathrm{s}, \mathrm{Fr}_{1}=6 \cdot 1, \operatorname{Re}=7 \cdot 3 \times 10^{6} ;(\mathrm{b})$ details of hydraulic jump roller free surface at the toe of Paradise dam spillway on 5 March 2013 (shutter speed: 1/2000 s); (c) hydraulic jump in the inlet of a minimum energy loss culvert along Norman Creek Brisbane (Australia) on 20 May 2009: $Q \approx 80 \mathrm{~m}^{3} / \mathrm{s}$;

(d) hydraulic jump on the submerged Haigslee-Fernvale Road (Australia) on 11 January 2011 
where $\rho$ is the water density, $\boldsymbol{g}$ is the acceleration of gravity, $Q$ is the water discharge, $d_{1}$ is the inflow depth and $\mathrm{Fr}_{1}$ is the inflow Froude number (Henderson, 1966; Tricker, 1965). A related application is the hydraulic jump in translation, also called a positive surge and a compression wave (Favre, 1935; Jaeger, 1956; Stoker, 1957). A geophysical application is a tidal bore, observed in a small number of funnel-shaped estuaries with macro-tidal conditions (Chanson, 2011; Lighthill, 1978; Tricker, 1965). Figure 2 shows photographs of tidal bores travelling upstream. Figures 2(a) and 2(b) were taken, respectively, at 14.8 and $32.4 \mathrm{~km}$ upstream of the City of Bordeaux (France), which is located itself $100 \mathrm{~km}$ upstream of the river mouth. Figure 2(c) shows the Qiantang River bore about $90 \mathrm{~km}$ downstream of the maximum upstream extent of bore propagation; at that location, the river was $2.6 \mathrm{~km}$ wide and the bore stretched across the full channel width.

A key feature of hydraulic jumps and bores is the rapid spatial and temporal deformations of the roller free surface, in response to the interactions between entrained air bubbles and turbulent structures. Simultaneous measurements of freesurface fluctuations and instantaneous void fraction demonstrated a coupling between free-surface fluctuations and local turbulent and two-phase flow properties (Leng and Chanson, 2016; Wang and Chanson, 2015a). The largest free-surface fluctuations were typically observed in the first half roller, and the maximum fluctuations increased with the inflow Froude number (Mouaze et al., 2005; Murzyn and Chanson, 2009). Despite a few pertinent studies (Brocchini and Peregrine, 2001a, 2001b; Chachereau and Chanson, 2011; Leng and Chanson, 2016), the interplay between turbulent flow properties and free-surface deformations was rarely considered in breaking jumps and bores.

It is the aim of this contribution to revisit the hydrodynamics of hydraulic jumps and bores with a marked roller. The first

2.

part of the paper is dedicated to the methodology and basic flow patterns when modelling physically the hydrodynamics of breaking jumps and surges, together with a review of the progresses to date in the literature. The next sections report on the state of the art of the studies focusing on the free-surface elevation, void fraction and velocity analysis under breaking bores and hydraulic jumps.

\section{Physical modelling and investigations}

\subsection{Presentation}

Analytical and numerical studies of breaking jumps and bores are complicated by the highly turbulent nature of the flow and the large number of relevant equations and parameters. The most advanced numerical simulations, typically based on direct numerical simulations, are very demanding in terms of computation time and facilities. More generally, any solution in terms of free surface and hydrodynamic properties is a real challenge due to the strong interface deformations, turbulence and air entrainment (Ma et al., 2011; Mortazavi et al., 2016; Richard and Gavrilyuk, 2013). The current expertise in hydraulic jumps relies heavily on laboratory investigations under controlled flow conditions (Chanson and Carvalho, 2015; Hager, 1992; Wood, 1991). This is especially important for ongoing developments of numerical modelling and the required validation (Carvalho et al., 2008; Gonzalez and Bombardelli, 2005; Lubin et al., 2009, 2010; Mortazavi et al., 2016). The validation of a numerical model is truly difficult (Rizzi and Vos, 1998; Roache, 1998, 2009) and relies on highquality physical data. In a complex situation typical of jumps and bores, the model outputs must be compared systematically against a range of detailed hydrodynamic characteristics.

Experimental investigations of hydraulic jumps and bores are not trivial despite advances in instrumentation since the first successful experiments by Bidone (1819). A fundamental challenge is the selection of suitable kinematic and dynamic similarities (Liggett, 1994; Novak and Cabelka, 1981). For a hydraulic jump, the relevant parameters include the physical properties and constants, the channel characteristics, the inflow conditions and the local flow properties at a location $(x, y, z)$ (Kobus, 1984; Wood, 1991). Considering a hydraulic jump in a prismatic, horizontal channel with inflow depth $d_{1}$ and velocity $V_{1}$ (Figure 3 ), a simplistic dimensional analysis yields the first approximation

$$
\begin{aligned}
& \frac{d}{d_{1}}, \frac{P}{\rho \boldsymbol{g} d_{1}}, \frac{V}{V_{1}}, \frac{v^{\prime}}{V_{1}}, C, \frac{F d_{1}}{V_{1}}, \frac{D_{a b}}{d_{1}}, \frac{N_{\mathrm{c}} d_{1}}{V_{1}}, \ldots \\
& \quad=f_{1}\left(\frac{x-X_{\mathrm{toe}}}{d_{1}}, \frac{y}{d_{1}}, \frac{z}{d_{1}}, \frac{V_{1}}{\sqrt{\boldsymbol{g} d_{1}}}, \rho \frac{V_{1} d_{1}}{\mu}, \frac{\boldsymbol{g} \mu^{4}}{\rho \sigma^{3}}, \frac{W}{d_{1}}, \frac{v_{1}^{\prime}}{V_{1}}, \frac{\delta_{1}}{d_{1}}, \frac{k_{\mathrm{s}}}{d_{1}}, \ldots\right)
\end{aligned}
$$

where $d$ is the water depth; $P$ is the pressure; $\rho$ is the water density; $\boldsymbol{g}$ is the acceleration of gravity; $V$ is the mean velocity; $v^{\prime}$ is a velocity fluctuation; $C$ is the void fraction; $F$ is the bubble count rate; $D_{a b}$ is a characteristic bubble size; $N_{\mathrm{c}}$ is the number of bubble clusters per second; $x, y$ and $z$ are the longitudinal, transverse and vertical coordinates, respectively; $X_{\text {toe }}$ is the mean jump toe position; $\mu$ is the water dynamic viscosity; 


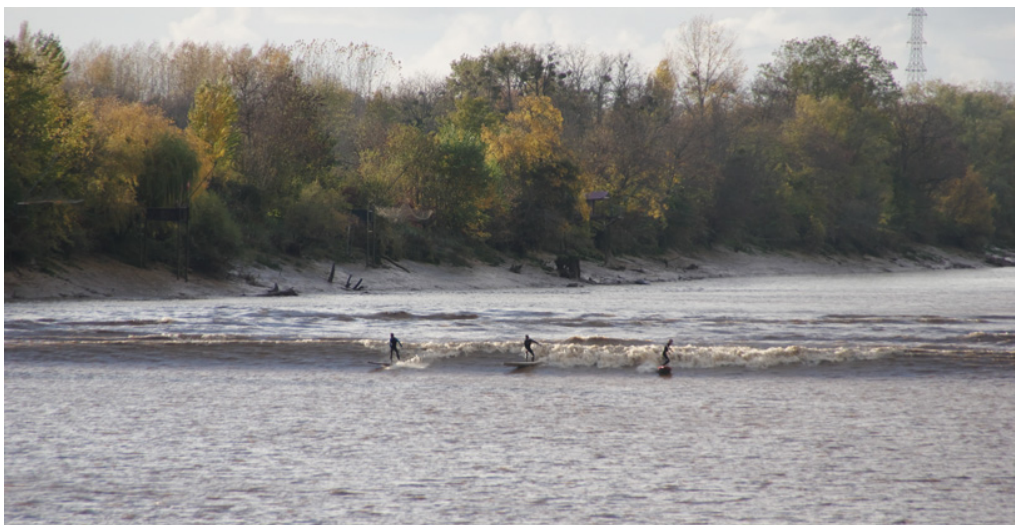

(a)

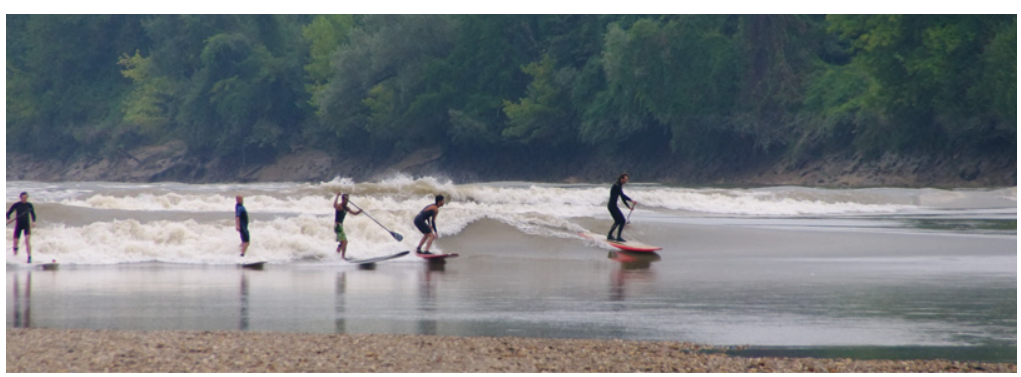

(b)

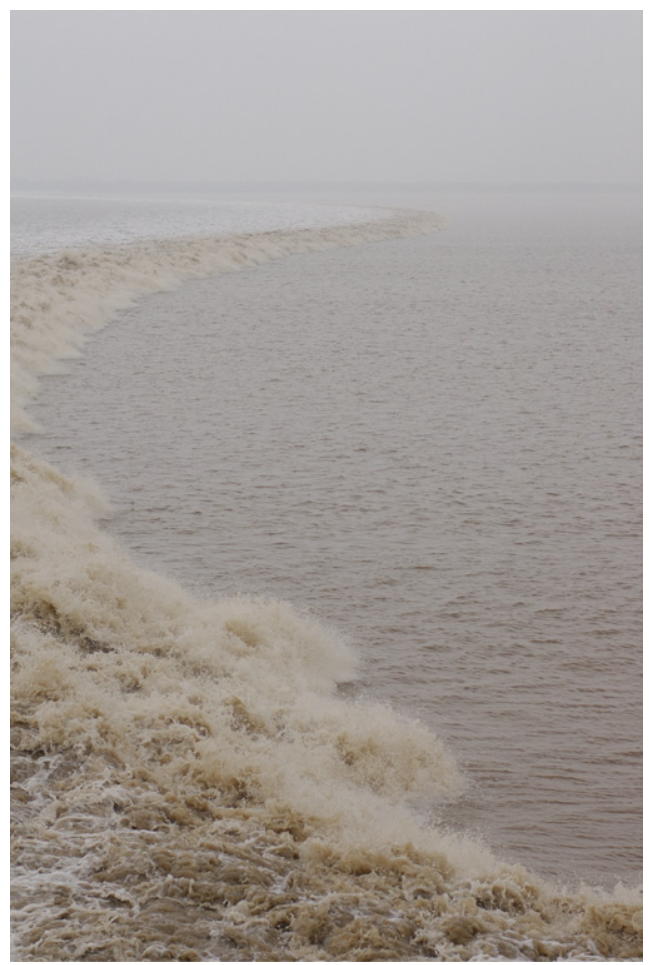

(c)
Figure 2. Tidal bores: (a) Garonne River bore at Cambes (France) on 28 October 2015 afternoon - looking downstream at the incoming bore; (b) Garonne River bore at Podensac (France) on 24 August 2013 morning - view from the left bank on the sand bank, made of coarse gravels and sand, looking downstream - this site is located $17.6 \mathrm{~km}$ upstream of Cambes (Figure 2(a)); (c) Qiantang River tidal bore at Yanguan (China) on 7 September 2013 - view from the left bank with upstream bore propagation from left to right $\sigma$ is the surface tension between air and water; $W$ is the channel width; $v_{1}^{\prime}$ is the inflow velocity fluctuations; $\delta_{1}$ is the inflow boundary layer thickness; and $k_{\mathrm{s}}$ is the equivalent sand roughness height. In Equation 2, the fourth, fifth and sixth terms on the right-hand side are, respectively, the inflow Froude number, the Reynolds number and the Morton number.

For a bore propagating in a prismatic, horizontal channel with initial flow depth $d_{1}$ and velocity $V_{1}$ (Figure 3 ), the same reasoning yields where $\bar{X}$ is the transverse-averaged roller toe position at time $t$ and $\bar{U}$ is the transverse-averaged bore celerity (Figure 3 ). In Equation 3, the fifth and sixth terms on the right-hand side are, respectively, the bore Froude number and Reynolds number, as defined in a system of coordinates travelling at the surge celerity.

For hydraulic jumps and bores, theoretical considerations based on mass and momentum conservation show the relevance of the Froude number (Bélanger, 1841; Chanson, 2012;

3.

$$
\frac{d}{d_{1}}, \frac{P}{\rho \boldsymbol{g} d_{1}}, \frac{V}{V_{1}}, \frac{v^{\prime}}{V_{1}}, C, \frac{F d_{1}}{V_{1}}, \frac{D_{a b}}{d_{1}}, \frac{N_{\mathrm{c}} d_{1}}{V_{1}}, \ldots
$$

$$
=f_{2}\left(\frac{x-\bar{X}}{d_{1}}, \frac{y}{d_{1}}, \frac{z}{d_{1}}, t \sqrt{\frac{\boldsymbol{g}}{d_{1}}}, \frac{\bar{U}+V_{1}}{\sqrt{\boldsymbol{g} d_{1}}}, \rho \frac{\left(\bar{U}+V_{1}\right) d_{1}}{\mu}, \frac{\boldsymbol{g} \mu^{4}}{\rho \sigma^{3}}, \frac{W}{d_{1}}, \frac{v_{1}^{\prime}}{V_{1}}, \frac{\delta_{1}}{d_{1}}, \frac{k_{\mathrm{s}}}{d_{1}}, \ldots\right)
$$



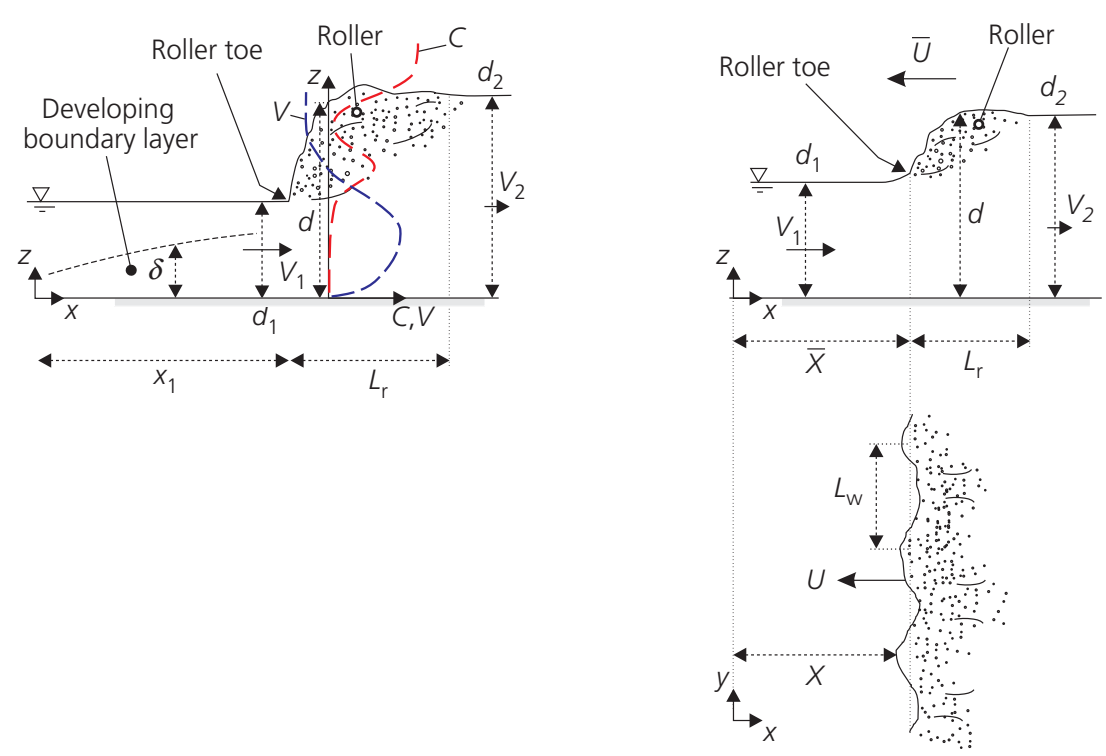

Figure 3. Definition sketch of hydraulic jump and bore with a marked roller

Lighthill, 1978): that is, the selection of a Froude similitude is implicit. However, the turbulent flow motion in the roller is dominated by viscous shear, and the bubble breakup and coalescence processes are further driven by capillary and inertial forces. A true similarity is thus impossible to achieve using a geometrically similar model with air and water in both prototype and model, unless working at full scale. In practice, the Froude and Morton similarities are simultaneously employed, albeit the Reynolds number is drastically underestimated in the laboratory, leading to viscous-scale effects in small-size models (Chanson, 2009b; Kobus, 1984; Wood, 1991). Herein both Froude and Morton number similarities were used and the experiments were conducted in large-size facilities operating at relatively large Reynolds numbers. These conditions may correspond to a 1:2-1:5 undistorted scale study of flow conditions shown in Figures 1(c), 1(d), 2(a) and 2(b), thus ensuring that any extrapolation of laboratory data to prototype conditions is unlikely to be adversely affected by significant scale effects.

\subsection{Experimental facilities}

Experimental measurements were conducted in two relatively large-size facilities located at the University of Queensland (Australia). Hydraulic jump experiments were conducted in a $3.2 \mathrm{~m}$ long, $0.5 \mathrm{~m}$ wide horizontal flume, made of smooth high-density polyethylene bed and glass sidewalls. The water was supplied by a constant head reticulation system feeding a large intake structure leading to the flume through a vertical, rounded sluice gate, with a semicircular rounding of $\varnothing=0.3 \mathrm{~m}$. Flow straighteners and baffles were installed in the intake structure to deliver a smooth quasi-two-dimensional approach flow upstream of the rounded gate, while the tailwater level in the flume was controlled by a vertical overshoot sluice located at the flume's downstream end. The bore experiments were performed in a $19 \mathrm{~m}$ long, $0.7 \mathrm{~m}$ wide tilting flume, made of glass sidewalls and smooth polyvinyl chloride bed. The channel was fed by an upstream water tank equipped with baffles and flow straighteners, leading the water to the flume through a smooth three-dimensional convergent intake. The bores were generated by rapidly closing a Tainter gate located next to the downstream end of the channel, and the bore propagated upstream against the initially steady flow motion. The gate closure time was $<0.2 \mathrm{~s}$ and had no effect on the bore properties.

The discharges were measured with a Venturimeter in the hydraulic jump flume and a magneto-flowmeter in the bore channel. In steady clear-water flows, the water elevations were measured using pointer gauges with an accuracy of $0.001 \mathrm{~m}$. The instantaneous water depths were recorded with a series of acoustic displacement meters (ADMs) Microsonic Mic $+25 /$ IU/TC and Mic+35/IU/TC, typically placed above the channel to sample non-intrusively the free-surface elevation and calibrated against pointer gauge measurements in steady clear-water flows. The applicability of ADM to breaking bores with air bubble entrainment was tested against sidewall dSLR photography and phase-detection probe data (Leng and Chanson, 2015a, 2015b; Wang and Chanson, 2015a). 
In clear-water flows, velocity measurements were conducted with a Prandtl-Pitot tube $(\varnothing=3.2 \mathrm{~mm})$ and an acoustic Doppler velocimeter (ADV) Nortek Vectrino+ equipped with a three-dimensional side-looking head. The latter was used in unsteady bore flows and sampled at $200 \mathrm{~Hz}$ synchronously with ADM sensors. Two-phase air-water flow measurements were performed intrusively with a dual-tip phase-detection probe $(\varnothing=0.25 \mathrm{~mm})$ sampled at $20 \mathrm{kHz}$ per sensor. In addition, very-high-speed video movies were recorded with a Phantom v711 ultra-high-speed camera, equipped with Nikkor $50 \mathrm{~mm} / 1.4 D$ lens to characterise the bubble formation and behaviour. The camera operated at up to 22000 frames per second (fps) with full high-definition (HD) resolution $(1280 \times 800$ pixels $)$. Video movies were taken through the sidewall, with a depth of field of $<20 \mathrm{~mm}$. Further observations were done using a Pentax $K-3$ dSLR camera (24 Mpixels), Casio Exilim EX-10 camera with movie mode set at $240 \mathrm{fps}$ $(512 \times 384$ pixels $)$, and an HD video camera Sony HDRXR160.

Experiments were conducted for a range of Froude numbers between 1.4 and $3 \cdot 8$, corresponding to Reynolds numbers between $3 \cdot 4 \times 10^{4}$ and $3 \times 10^{5}$ (Table 1). Table 1 summarises the experimental flow conditions.

\section{Basic flow patterns and air entrainment processes}

The key features of breaking jumps and bores include the highly fluctuating nature of the flow motion, strong threedimensional turbulence with the presence of large vortical structures resulting from vortex pairing in the shear layer, air bubble entrainment, spray and splashing above the pseudo-free-surface including overturning air-water structures. Figure 4 presents two high-shutter-speed photographs of a hydraulic jump with marked roller (Figure 4(a)) and a breaking bore propagating upstream (Figure 4(b)). A large amount of air bubbles and packets are entrapped at the impingement of the inflow free surface with the roller. The entrained air is advected in a developing shear layer, the roller toe representing a flow singularity in terms of air bubble entrainment and vorticity generation. The roller toe is constantly changing in shape in response to the roller surface deformation and turbulence (Leng and Chanson, 2015a; Wang and Chanson, 2015b; Zhang et al., 2013). The rapid change in roller free surface is associated with additional interfacial exchanges between air and water, and the roller region is highly aerated.

\subsection{Air entrainment mechanisms in breaking jumps and bores}

A hydraulic jump may be comparable to a translating bore when its inflow Froude number satisfies $\mathrm{Fr}_{1}<4$. With partially developed inflow conditions, as in this study, a stationary breaking jump was observed when the inflow Froude number was $>2 \cdot 1-2 \cdot 8\left(\operatorname{Re} \sim 3 \times 10^{4}\right)$. When the Froude number was slightly larger than this critical value, a relatively short roller formed between the jump toe and the downstream quasiuniform tailwater motion. The dimensionless roller length, free-surface profile and dimensionless surface fluctuation magnitude were functions of the Froude number (see the next section), while the air entrainment, bubble grouping and turbulent mixing were further affected by the Reynolds number of the impinging flow.

Flow visualisation showed that the air entrainment mechanisms and processes of a breaking tidal bore with $\mathrm{Fr}_{1}>1.5$ was very similar to those of a breaking hydraulic jump with low Froude numbers. When a breaking roller was formed, air entrainment occurred immediately at the free-surface discontinuity. The entrainment of air bubbles and large air pockets was associated with both the recirculating motion above the roller toe and the balance between air-water surface tension and turbulent shear stress next to the air-water interface. Ultra-high-speed video movies highlighted similar air entrainment mechanisms in jumps and bores, albeit different mechanisms were observed depending on different turbulence levels. Figure 5 illustrates three most typical air entrainment mechanisms, without considering the pre-aeration of the impinging flow. The first mechanism (Figure 5(a)) was featured by the formation of elongated air cavities at the toe as the impinging flow running into the roller. An air layer formed next to the

\begin{tabular}{lllllc}
\hline Flow configuration & W: $\mathrm{m}$ & Q: $\mathrm{m}^{3} / \mathrm{s}$ & $d_{1}: \mathrm{m}$ & $\mathrm{Fr}_{1}$ & $\mathrm{Re}$ \\
\hline Hydraulic jump (HJ) & 0.50 & 0.017 & 0.020 & 3.8 & $3.4 \times 10^{4}$ \\
& & 0.034 & 0.032 & 3.8 & $6.8 \times 10^{4}$ \\
Breaking bore (BB) & 0.70 & 0.081 & 0.057 & 3.8 & $1.6 \times 10^{5}$ \\
& & 0.101 & $0.10-0.18$ & $1.5-2 \cdot 1$ & $2 \times 10^{5}$ to $3 \times 10^{5}$ \\
& & 0.085 & $0.15-0.16$ & $1.4-1.5$ & $3 \times 10^{5}$
\end{tabular}

Table 1. Summary of experimental flow conditions

(present study) 


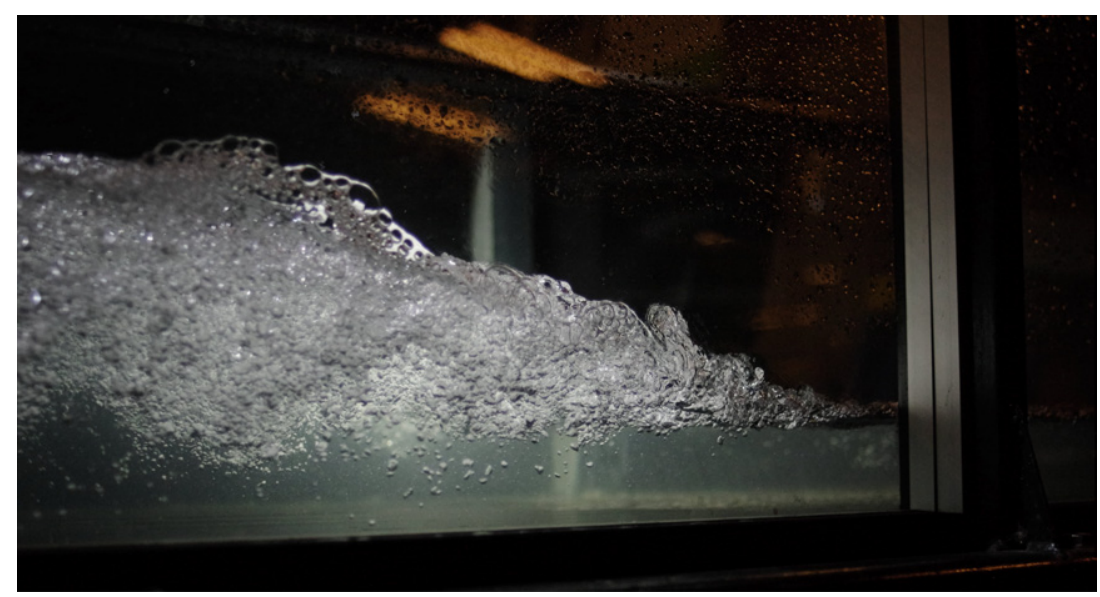

(a)

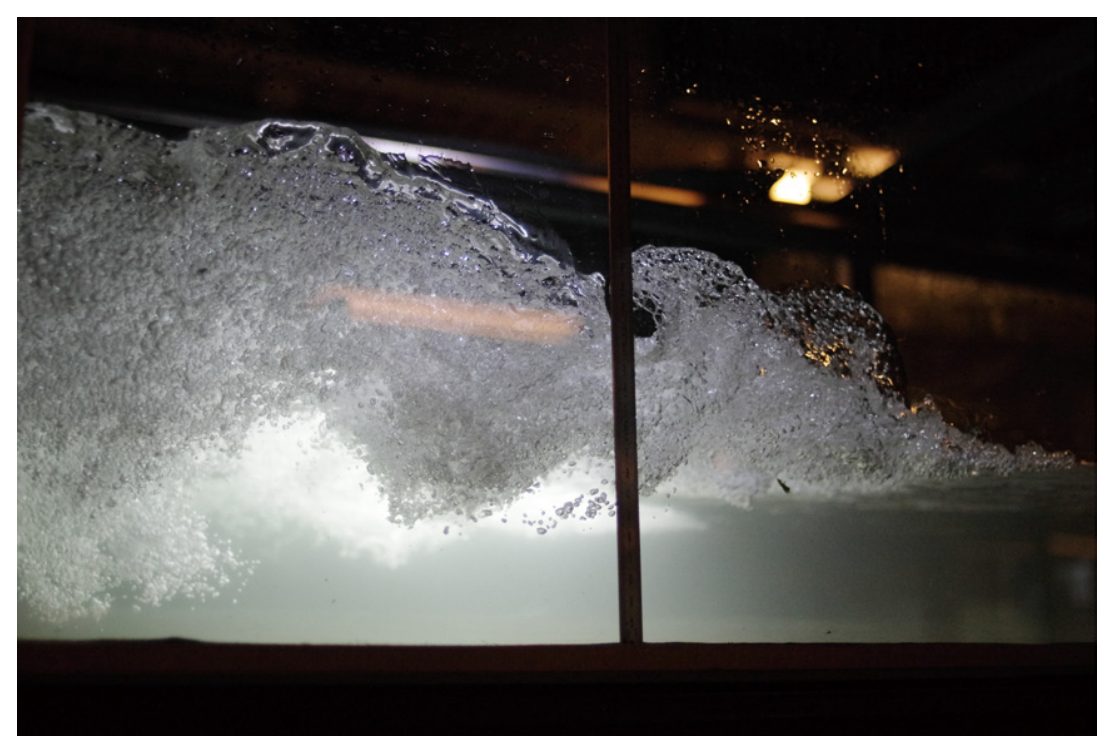

(b)

Figure 4. Air entrainment in the roller: side views of hydraulic jump and bore - high-shutter speed photography with backlighting: (a) hydraulic jump - steady flow direction from right to left, flow conditions: $\operatorname{Fr}_{1}=3, \operatorname{Re}=1 \cdot 2 \times 10^{5}$, shutter speed:
1/5000 s; (b) breaking bore propagating upstream - bore front propagation from left to right, flow conditions: $\mathrm{Fr}_{1}=2 \cdot 2$, $\operatorname{Re}=2 \cdot 1 \times 10^{5}$, shutter speed: $1 / 5000 \mathrm{~s}$ inflow free surface due to the no-slip condition. The air layer intruded into the roller at the impingement point, inducing an air cavity that was elongated into an air finger and pinched off by the weight of the surrounding water, the shear stress or some secondary twisting motions of the fluid. The detached air pockets were advected downstream, broken into finer bubbles and driven upwards to the roller surface. The second mechanism (Figure 5(b)) was related to the flow reversal at the toe, where air was entrapped when the reversing water plunged into the impinging flow. Unlike the first mechanism when air bubbles were mostly entrained into the upper roller above the shear layer, the bubbles entrapped by the reversing flow motion were first driven into the lower shear flow region, where they experienced intense turbulence and breakup/ coalescence processes. The two mechanisms took place broadly in all breaking jumps and bores irrespective of how turbulent the flow was. For larger Reynolds numbers, high disturbance was seen in the impinging flow and the roller surface deformation was substantial, with projection of droplets and foams in the air. In this case (third mechanism), large-scale turbulence consisting of large vortices typical of billows generated by Kelvin-Helmholtz shear instability became the predominant 


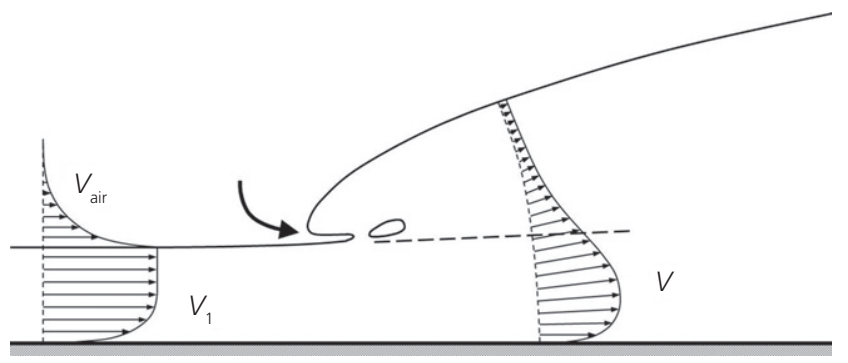

(a)

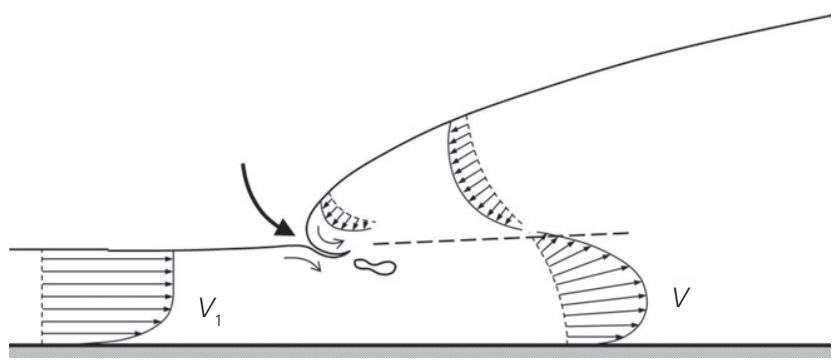

(b)

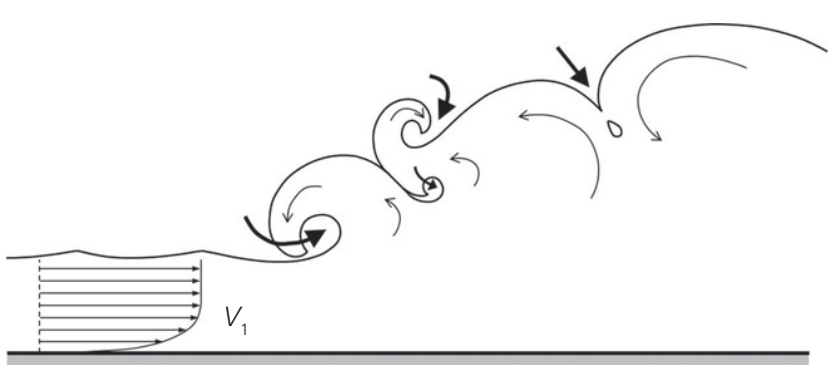

(c)

Figure 5. Sketches of air entrainment mechanisms in hydraulic jumps - similar mechanisms apply to breaking bores: (a) air layer intruding into roller; (b) air entrapment by reversing flow at roller toe; (c) air entrapment and air-water exchange for highdisturbance impinging flow

factor that drove the air entrainment both at the impingement point and through the roller surface (Figure 5(c)). Large air cavities formed at the impingement point following the arrival of peak inflow disturbances. The air cavities were closed by the recirculating flow, and the entrapped air pockets were broken into small bubbles and advected downstream in large vortices. Herein the formation of large vortices is also known as some Kelvin-Helmholtz instability. A large portion of bubbles was involved in roller recirculation. Those bubbles recirculating back to the roller toe were re-entrained into the shear layer. Some foamy air-water structures were projected upstream over the impingement point, interfering with the impinging jet surface and enhancing the inflow disturbance at the toe. The convective large vortical structures in the shear layer further interacted with the roller surface and enhanced the interfacial air-water exchange. That is, when two vortices were convected in a pair, the reversing front of the leading vortex might collide with the shield of the trailing vortex, resulting in severe surface breaking and splashing (Figure 5(c)). The collision planes were observed in $45^{\circ}$ with the horizontal, consistent with the numerical simulations of Lubin and Glockner (2015). A good amount of air was entrained in the cavities generated by the spray and surface deformation.

\section{Free-surface properties}

\subsection{Longitudinal roller surface profile}

Stationary hydraulic jumps exhibit a self-similar roller surface profile shape for a wide range of inflow conditions. The timeaveraged surface profile of hydraulic jumps with a marked roller may be approximated as

4a. $\frac{d}{d_{1}}=1$ for $\frac{x-x_{1}}{L_{\mathrm{r}}}<0$

4b. $\frac{d-d_{1}}{d_{2}-d_{1}}=\left(\frac{x-X_{\text {toe }}}{L_{\mathrm{r}}}\right)^{0.537}$ for $0<\frac{x-x_{1}}{L_{\mathrm{r}}}<1$

4c. $\frac{d_{2}}{d_{1}}=\frac{1}{2} \times\left(\sqrt{1+8 \mathrm{Fr}_{1}^{2}}-1\right)$ for $\frac{x-x_{1}}{L_{\mathrm{r}}}>1$

4d. $\frac{L_{\mathrm{r}}}{d_{1}}=6\left(\mathrm{Fr}_{1}-1\right)$ for $\mathrm{Fr}_{1}<10$

where $d_{2}$ is the tailwater depth and $L_{\mathrm{r}}$ is the jump roller length over which the water level increases monotonically from $d_{1}$ to $d_{2}$. Equation $4 \mathrm{~b}$ is an empirical fit of non-intrusive water elevation measurement results for $3.8<\mathrm{Fr}_{1}<10,3.5 \times 10^{4}<$ $\operatorname{Re}<1 \cdot 6 \times 10^{5}$ (Wang and Chanson, 2016). Equation $4 \mathrm{c}$ is the solution of momentum equation in a smooth, horizontal, rectangular channel (Bélanger, 1841). The dimensionless roller length $L_{\mathrm{r}} / d_{1}$ follows a linear function of the Froude number for $\mathrm{Fr}_{1}<10$ (Figure 4(d)).

Equation 4 indicates that the dimensionless free-surface profile of a hydraulic jump is determined by its Froude number. Figure 6(a) compares Equation 4 with the experimental data for three jumps with identical Froude number $\mathrm{Fr}_{1}=3.8$ and different Reynolds numbers. In addition to the time-averaged 


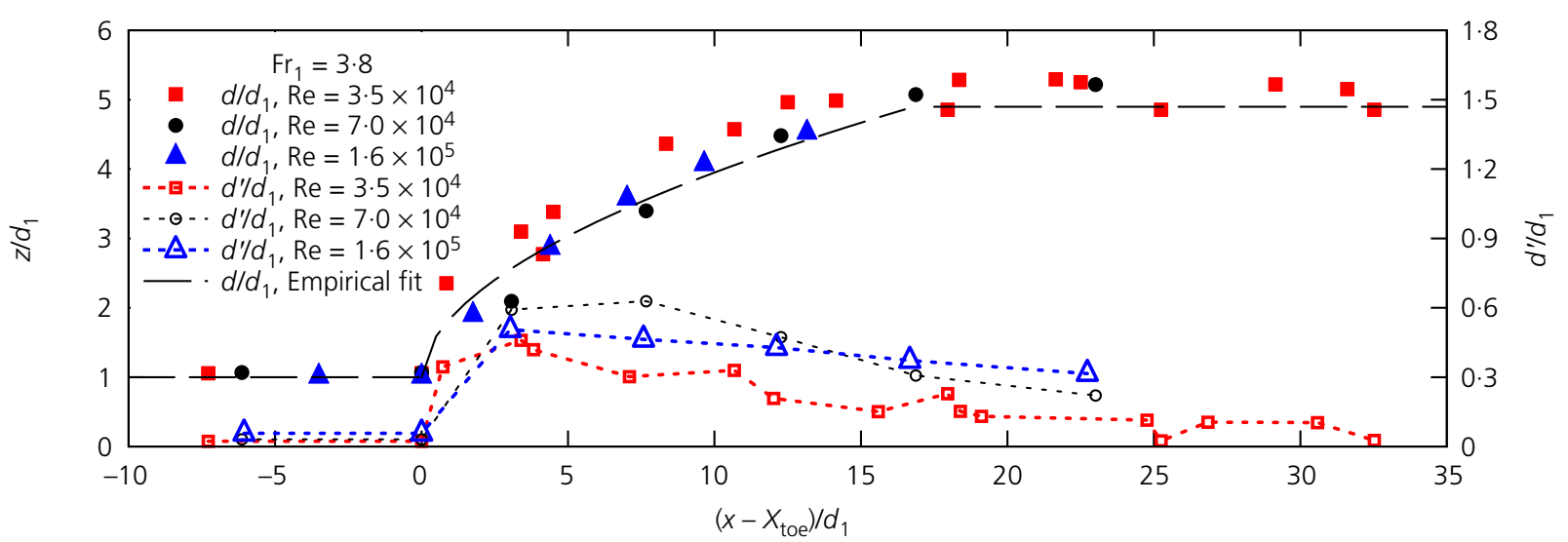

(a)

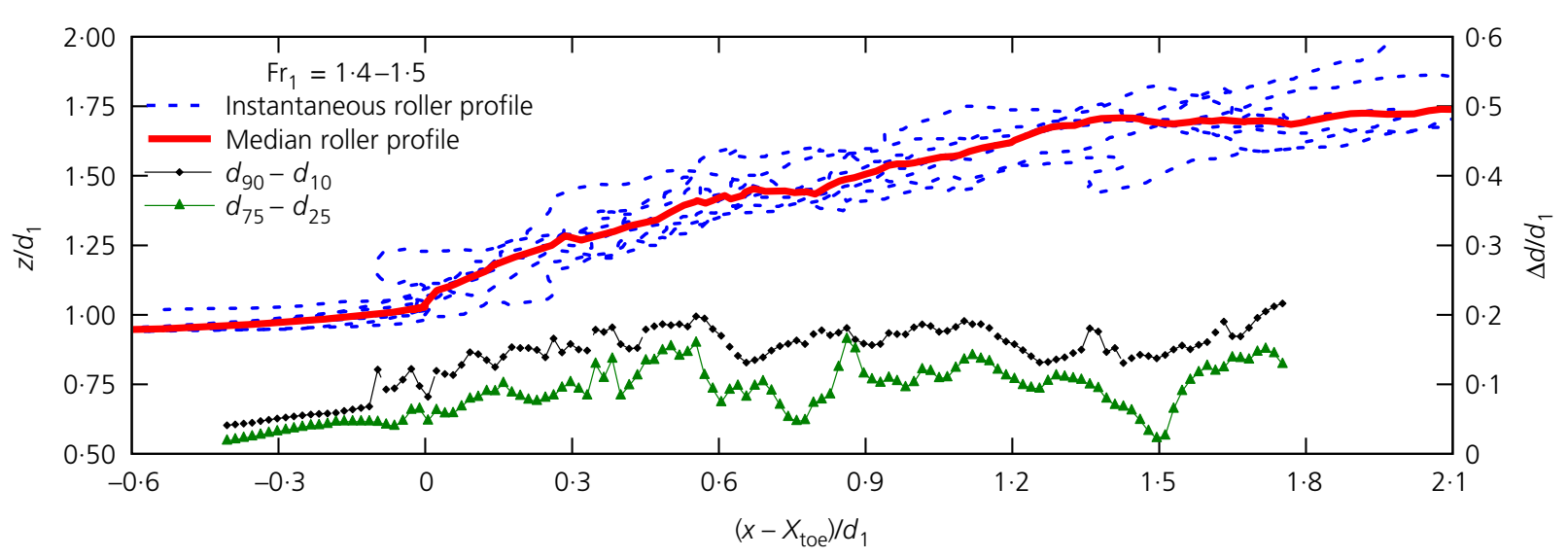

(b)

Figure 6. Hydraulic jump and bore roller surface profile and fluctuations: (a) time-averaged roller surface profile and depth standard deviation of hydraulic jump $-\mathrm{Fr}_{1}=3 \cdot 8$,
$3.4 \times 10^{4}<\operatorname{Re}<1.6 \times 10^{5} ;$ (b) instantaneous and median roller surface profiles and profile fluctuations of breaking bore $\mathrm{Fr}_{1}=1 \cdot 4-1 \cdot 5, \mathrm{Re}=3 \times 10^{5}$ water depth $d$, the depth fluctuations are also presented with the standard deviation of instantaneous water elevation data $d^{\prime}$. Figure 6(b) shows a series of instantaneous roller surface profiles of a breaking bore together with the median profile. The instantaneous free-surface fluctuations were quantified by the difference between the ninth and first deciles $\left(d_{90}-d_{10}\right)$ and the difference between the third and first quartiles $\left(d_{75}-d_{25}\right)$. For a data set with a Gaussian distribution around its mean, $\left(d_{90}-d_{10}\right)$ and $\left(d_{75}-d_{25}\right)$ would be equal to 2.6 and 1.3 times the standard deviation, respectively (Spiegel, 1974). For both stationary jump and translating bore, the maximum roller surface fluctuations were observed in the first half of roller, and its magnitude increased with increasing Froude number, following a similar trend (Figure 7). With stationary hydraulic jumps, spectral analyses further indicated that the dimensionless fluctuation frequency of the roller toe decreased with increasing Froude number and increased with increasing Reynolds number in hydraulic jumps (Wang and Chanson, 2016).

In stationary hydraulic jumps, the fluctuations of roller depth (i.e. in the vertical direction) were associated with the roller surface deformation, which was coupled to a longitudinal oscillation of jump toe position $X_{\text {toe. }}$ An uplifted roller surface position was typically coupled with a downstream shifting of jump toe position and vice versa (Wang and Chanson, 2015a). The jump toe oscillation magnitude in the horizontal direction was larger than and proportional to the maximum vertical depth fluctuation. The characteristic frequency of toe oscillation was $\sim 0.4$ times that of depth fluctuation, and the Strouhal number was subject to similar effects of the Froude and Reynolds numbers. 


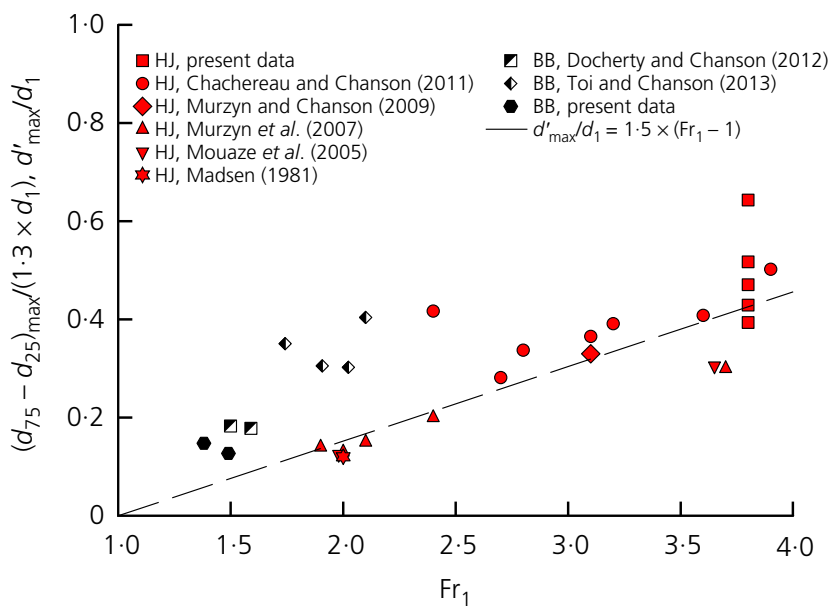

Figure 7. Comparison of maximum roller surface fluctuations between weak hydraulic jumps and breaking bores $\left(\mathrm{Fr}_{1}<4\right)$

\subsection{Transverse roller toe perimeter}

With breaking tidal bores, the bore roller propagates upstream with a mean bore celerity $\bar{U}$, albeit the instantaneous celerity $U$ varies rapidly in both time and transverse location. Viewed in elevation, the toe of the roller forms a continuous curvy shape called the roller toe perimeter, the toe being the location of flow singularity where the abrupt depth rise takes place (Figure 3). Measurements of the roller toe perimeter were conducted using high-speed video cameras, and the toe perimeter shape was digitalised frame by frame. Figure 8(a) shows a typical photograph of a breaking bore propagating in a laboratory channel viewed from the top, and Figure 8(b) presents typical instantaneous roller toe perimeter evolution with time, in the $x-y$ plane, with $x$ being the real-scale longitudinal distance from the start of the frame and $y$ the real-scale transverse distance from the right sidewall. The data featured a wide range of instantaneous shapes of the roller toe perimeter, which varied rapidly in both longitudinal and transverse directions, hence with time. The motion of the roller toe perimeter demonstrated a quasi-two-dimensional fluctuating behaviour, and the data highlighted backshifts of the toe from time to

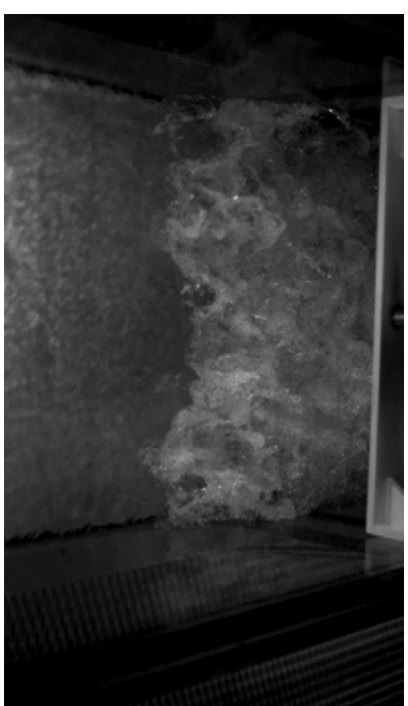

(a)

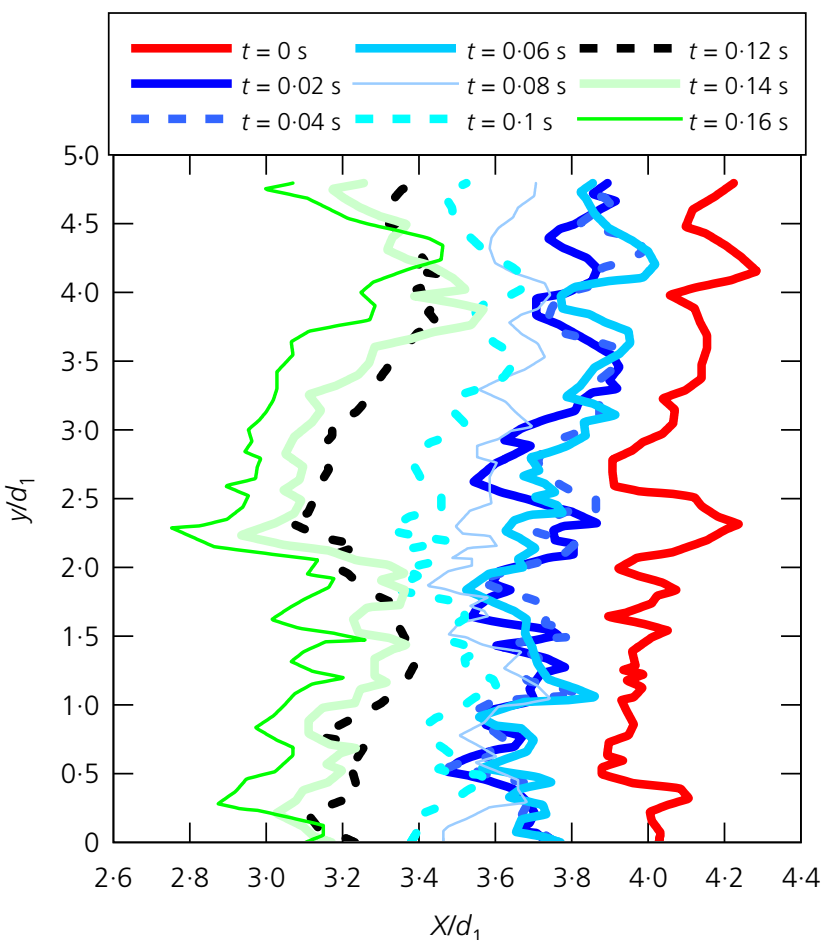

(b)
Figure 8. Transverse profile of the instantaneous roller toe perimeter of a breaking bore: (a) photographic snapshot of roller toe perimeter (viewed in elevation) - bore propagation from right to left, breaking bore: $\mathrm{Fr}_{1}=2 \cdot 1$; (b) instantaneous undistorted transverse profiles of roller toe perimeter for a breaking bore $\left(F r_{1}=1 \cdot 5\right)$ - data analysis from $50 \mathrm{fps}$ video 


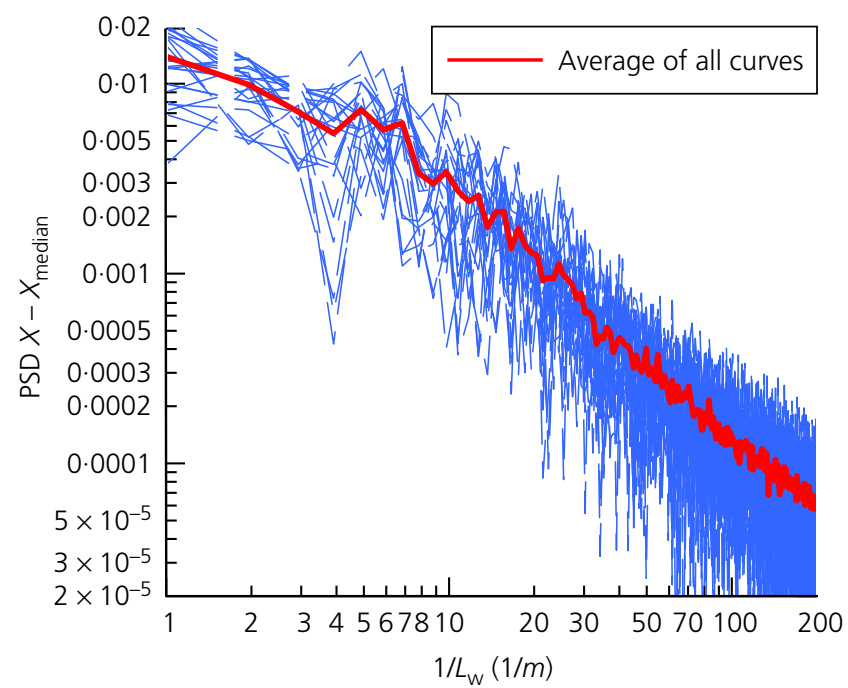

Figure 9. Power spectral density of function of the transverse fluctuations in roller toe perimeter about its median position (single video data at $50 \mathrm{fps}$ )

time, in particular using high frame rates (i.e. $50 \mathrm{fps}$ and more).

The transverse profile of roller toe perimeter (Figure 8 ) presented some pseudo-periodicity, implying the existence of a characteristic transverse wavelength $L_{\mathrm{w}}$. The definition of $L_{\mathrm{w}}$ is illustrated in Figure 3. The characteristic wavelength $L_{\mathrm{w}}$ was analysed by performing fast Fourier transformations on the fluctuations of the roller toe perimeter, defined as the deviation of the instantaneous toe position to its spatial median calculated in the transverse direction. Typical results are shown in Figure 9. In Figure 9, the data highlighted two characteristic peaks corresponding to $L_{\mathrm{W}}=0 \cdot 2$ and $0 \cdot 146 \mathrm{~m}$, respectively. Altogether, the data set tended to show a predominant dimensionless wavelength of $L_{\mathrm{w}} / d_{1} \sim 1 \cdot 2$. For comparison, studies in the Qiantang River tidal bores (Figure 2(c)) documented a transverse wavelength range of $0 \cdot 7<L_{\mathrm{w}} / d_{1}<25$, with two predominant wavelengths of $L_{\mathrm{w}} / d_{1} \sim 1$ and 5-10 (Leng and Chanson, 2015a). In stationary hydraulic jumps, Zhang et al. (2013) reported dimensionless transverse wavelengths of roller toe perimeters $L_{\mathrm{w}} / d_{1}$ ranging from 0.7 to 7 , even though the time-averaged perimeter was a straight line on average.

In addition to the characteristic transverse wavelength, another length scale of turbulent structures is the integral turbulent length scale, which represents the average dimension of coherent flow structures weighted by the correlation coefficient between samples collected repeatedly at different locations. Measurements were performed in stationary hydraulic jumps

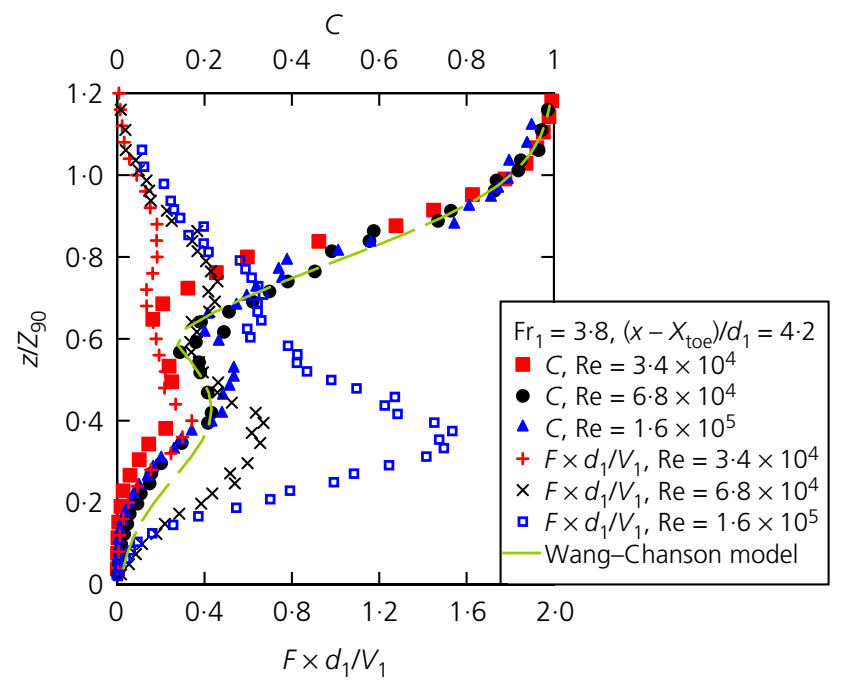

Figure 10. Vertical distributions of time-averaged void fraction and bubble count rate in hydraulic jump close to the toe comparison with analytical void fraction prediction for $\mathrm{Fr}_{1}=3 \cdot 8$, $\left(x-X_{\text {toe }}\right) / d_{1}=4 \cdot 2$

for a variety of flow properties. The coherent structure in the fluctuating wave-like jump toe perimeter had an integral length scale between $2 \times d_{1}$ and $5.5 \times d_{1}$, depending on the Froude number (Wang and Murzyn, 2016). This was larger than the integral length scale of free-surface turbulent structures, either in longitudinal or transverse direction, which increased from $0.5 \times d_{1}$ close to the toe to $3 \times d_{1}$ at the downstream end of the roller (Chachereau and Chanson, 2011; Murzyn et al., 2007).

\section{Air-water flow properties}

A number of common features are shared between the air entrainment processes in weak hydraulic jumps and breaking bores. While the air-water flow properties of stationary hydraulic jumps are well documented (Chanson and Brattberg, 2000; Chanson and Carvalho, 2015; Murzyn et al., 2005; Wang and Chanson, 2015a, 2015b), air-water flow measurements in tidal bores were extremely challenging and limited due to the highly unsteady nature of the phenomenon. Herein the typical results of basic air-water flow properties in hydraulic jumps, including the local void fraction, bubble count rate and bubble size distributions, are presented together with preliminary Eulerian measurement results in the roller region of breaking bores. All measurements were performed using a dual-tip phase-detection probe.

Figure 10 shows typical distributions of time-averaged void fraction $C$ and bubble count rate $F$ in the hydraulic jump 
roller, where $Y_{90}$ is the elevation of $C=0.9$. The data were measured in a vertical cross-section downstream of and close to the jump toe $\left(\left(x-X_{\text {toe }}\right) / d_{1}=4 \cdot 2\right)$, with identical Froude number $\left(\mathrm{Fr}_{1}=3 \cdot 8\right)$ but different Reynolds numbers. The data profiles highlighted two flow regions, namely, the shear flow region where both void fraction and bubble count rate exhibited local maximum values, and the free-surface region above in which the void fraction increased monotonically to unity and the bubble count rate decreased to zero in the upper freesurface region. The presence of local maximum void fraction and bubble count rate in the shear flow region featured the singular air entrainment at the jump toe, followed by the development of a bubble diffusion layer and a turbulent shear layer. For a small Froude number, flow deaeration and turbulence dissipation took place within a short distance downstream of the toe. An analytical model of void fraction distributions in hydraulic jump roller may be proposed for steady to strong jumps $\left(3 \cdot 8<\mathrm{Fr}_{1}<10\right)$ (Wang and Chanson, 2016)

5a. $C=C_{\max } \exp \left(-\frac{V_{1}}{4 \times D_{\mathrm{t}}^{(\mathrm{s})}} \frac{\left(z-Z_{C_{\max }}\right)^{2}}{\left(x-X_{\mathrm{toe}}\right)}\right)$ for $z<Z_{C \min }$

5b. $\quad C=\frac{1}{2}\left(1+\operatorname{erf}\left(\frac{\sqrt{V_{1}}}{2 \sqrt{D_{\mathrm{t}}^{(\mathrm{r})}}} \frac{z-Z_{50}}{\sqrt{x-X_{\mathrm{toe}}}}\right)\right)$ for $z>Z_{C \min }$

where $Z_{C \text { min }}$ is the vertical position of local minimum void fraction at the boundary between turbulent shear flow and free-surface regions. The key parameters satisfy the following relationships (Wang and Chanson, 2016)

5c. $\quad C_{\max }=0.5 \exp \left(-3.4 \frac{x-X_{\mathrm{toe}}}{L_{\mathrm{r}}}\right)$

5d. $\quad \frac{Z_{C_{\max }}-d_{1}}{d_{2}-d_{1}}=0.56 \frac{x-X_{\text {toe }}}{L_{\mathrm{r}}}$

5e. $\quad \frac{Z_{50}-d_{1}}{d_{2}-d_{1}}=\left(\frac{x-X_{\text {toe }}}{L_{\mathrm{r}}}\right)^{0.536}$

5f. $\frac{D_{\mathrm{t}}^{(\mathrm{s})}}{V_{1} d_{1}}=0 \cdot 1\left(1-\exp \left(-2 \cdot 3 \frac{x-X_{\text {toe }}}{L_{\mathrm{r}}}\right)\right)$

5g. $\frac{D_{\mathrm{t}}^{(\mathrm{r})}}{V_{1} d_{1}}=0 \cdot 1 \exp \left(-3 \cdot 56 \frac{x-X_{\mathrm{toe}}}{L_{\mathrm{r}}}\right)$

with the roller length $L_{\mathrm{r}} / d_{1}=6 \times\left(\mathrm{Fr}_{1}-1\right)$ (Equation $\left.4 \mathrm{~d}\right)$. For a given Froude number and longitudinal position, the corresponding model prediction is plotted in Figure 10 and compared with experimental data. The void fraction distribution model provided close agreement with a broad range of flow conditions, although not always for weak jumps in the vicinity of jump toe when the Reynolds number was substantially

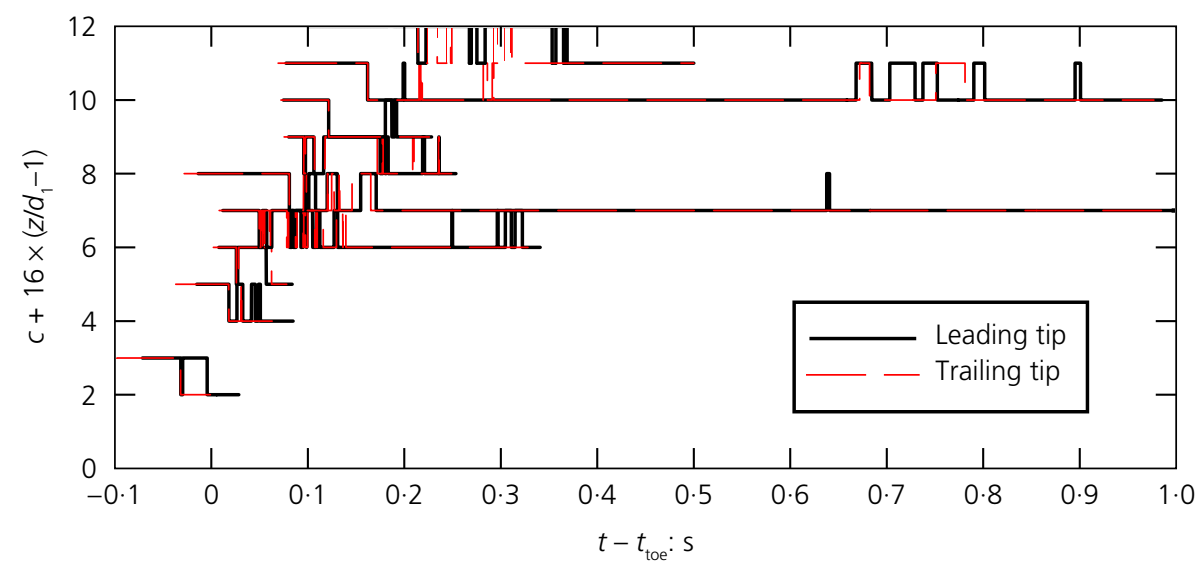

Figure 11. Instantaneous void fraction c measured at different vertical elevations in a breaking bore - flow conditions: $\mathrm{Fr}_{1}=1.4$, $\operatorname{Re}=3 \times 10^{5}$ 


\begin{tabular}{|l|l|l|l|l|l|l|}
\hline & $\mathrm{Fr}_{1}$ & $\operatorname{Re}$ & $\left(x-X_{\text {toe }} / d_{1}\right.$ & $z / d_{1}$ & $C$ & $F=F_{\max }: \mathrm{Hz}$ \\
\hline $\mathrm{HJ}$ & 3.8 & $3.4 \times 10^{4}$ & 12.5 & 2.55 & 0.009 & 2.7 \\
\hline $\mathrm{HJ}$ & 3.8 & $6.8 \times 10^{4}$ & 12.5 & 1.63 & 0.027 & 11.3 \\
\hline $\mathrm{HJ}$ & 3.8 & $1.6 \times 10^{5}$ & 12.5 & 1.93 & 0.040 & 26.9 \\
\hline $\mathrm{BB}$ & 1.5 & $2.6 \times 10^{5}$ & - & $1.4-1.5$ & - & - \\
\hline
\end{tabular}

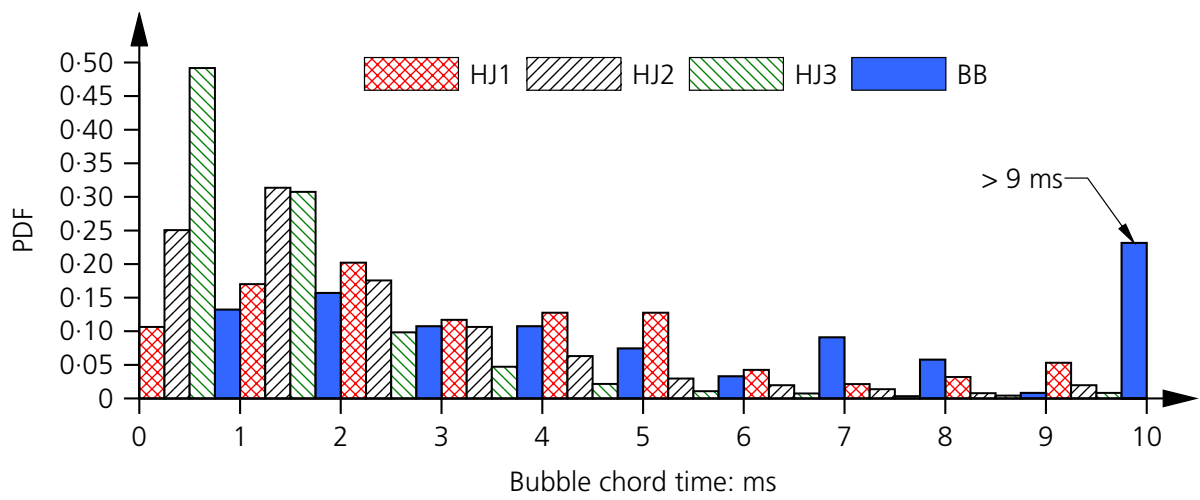

Figure 12. Probability density functions of bubble chord time in hydraulic jumps at vertical position of maximum bubble count rate and in breaking bore at all elevations - flow conditions

small. Recent studies have suggested that physical modelling of hydraulic jumps should be conducted with the Reynolds number greater than $4 \times 10^{4}$ to $6 \times 10^{4}$ to minimise viscousscale effects on void fraction measurements (Chanson and Gualtieri, 2008; Murzyn and Chanson, 2008; Wang and Chanson, 2016). Further, the bubble count rate, which is related to the air-water interfacial area, could be only accurately measured at full scale under Froude similitude with the same fluids in model and prototype.

In the translating bore, only time variations of the instantaneous void fraction $c$ were obtained at different vertical elevations in the breaking roller, as illustrated in Figure 11. The instantaneous void fraction is 0 in water and 1 in air; both signals of the leading and trailing phase-detection sensors are shown in Figure 11. The data showed a large amount of air bubbles entrained at vertical elevations between $1.25<z / d_{1}<$ 1.5. No bubbles were detected for $z / d_{1}<1 \cdot 05$. For higher elevations $z / d_{1}>1 \cdot 5$, the signals became intermittent due to interactions with the roller free surface. As shown in Figure 11, the detection of the first air-to-water interface was delayed with increasing vertical elevation. The trailing tip was sometimes associated with a detection of the first air-water interface earlier than that of the leading tip, implying possibly a negative instantaneous celerity, as observed in the analysis of the roller toe perimeter.

The instantaneous void fraction data showed a wide spectrum of bubble chord lengths and time in both bores and hydraulic jumps. Figure 12 illustrates the probability density functions of bubble chord time in hydraulic jumps $\left(\mathrm{Fr}_{1}=3.8\right)$ at a single characteristic elevation corresponding to maximum bubble count rate $\left(z=z\left(F_{\max }\right)\right)$, and in breaking bores $\left(\mathrm{Fr}_{1}=1 \cdot 4-1 \cdot 5\right)$ at several elevations. All data showed a right-skewed unimodal distribution, with the mode at about 1-2 ms. Large chord times $(>20 \mathrm{~ms})$ were observed, mostly at higher vertical elevations. Taking into account the average local velocity, the bubble chord time spectra corresponded to typical bubble size distributions from less than a millimetre to a centimetre. In particular, in the shear flow region of hydraulic jumps, a larger percentage of small-size bubbles were seen at the highest Reynolds number, likely caused by enhanced turbulent shear forces inducing the breakup of large bubbles.

\section{Velocity measurements}

The use of ADV enabled instantaneous sampling of local turbulent velocity in tidal bores with limited air entrainment, below the initial water level. As the propagation of tidal bores is an unsteady process, the time-averaging technique was not applicable, and the ensemble-averaging technique was used, in which experiments were repeated 25 times for a single flow configuration and ensemble-median properties were extracted. The fluctuations of turbulent characteristics in bores were calculated using the difference between the third and first quartile (Spiegel, 1974). On the other hand, the presence of numerous air bubbles hindered direct measurement of water velocity in hydraulic jumps, and the velocity characterisation relied largely 
on the detection of advected air-water interfaces using dual-tip phase-detection probes. Such a dual-tip phase-detection probe provided time-averaged interfacial velocity in the longitudinal direction. The interfacial velocity fluctuations in hydraulic jumps were deduced from a correlation analysis of probe signals (Chanson and Toombes, 2002), the results being a spatial-averaged value between the two probe sensors, affected by all turbulent flow motions relative to the probe (Wang et al., 2014).

Figure 13 presents typical interfacial velocity measurement results $V_{x} / V_{1}$ in hydraulic jumps, for the same flow conditions and locations as those in Figure 10. With a small inflow Froude number, flow reversal in the upper flow region took place only within a short distance downstream of the jump toe. That is, the length of the reversing flow (with negative freesurface velocity) was significantly smaller than the overall length of the jump roller. At the given longitudinal position corresponding to Figure 13, negative velocities were observed between $z / Z_{90}=0.6$ and 1 for the two largest Reynolds numbers, while no local flow reversal motion was detected for the smallest Reynolds number with the same Froude number. The absence of negative velocity was associated with the dissipation of large vortices in the shear layer and an absence of vortex-surface interaction beyond the measurement location, when the impinging flow was substantially less turbulent.

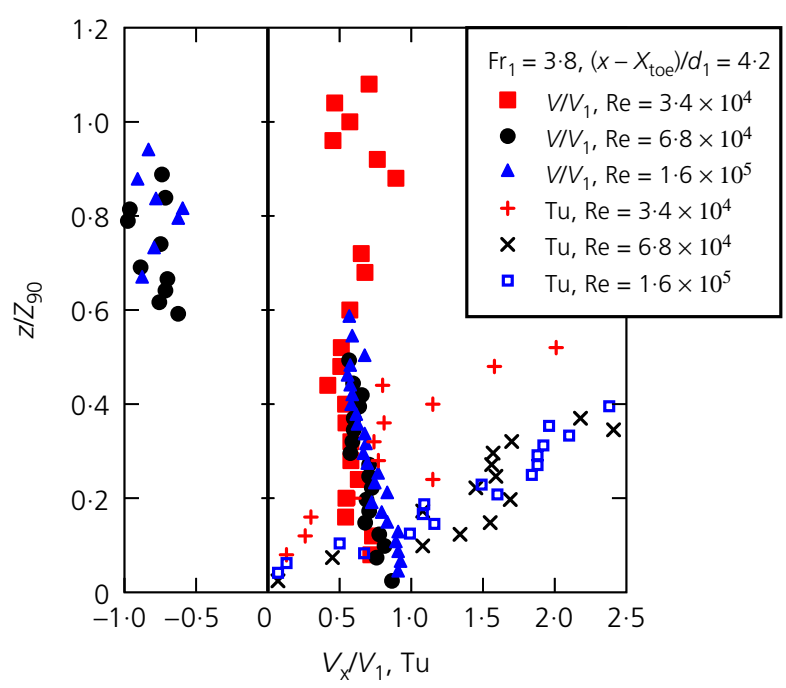

Figure 13. Vertical distributions of time-averaged interfacial velocity and turbulence intensity in hydraulic jump close to the toe - flow conditions: $\mathrm{Fr}_{1}=3 \cdot 8,\left(x-X_{\text {toe }}\right) / d_{1}=4 \cdot 2$,

$3.4 \times 10^{4}<\operatorname{Re}<1.6 \times 10^{5}$
Figure 13 also plots the interfacial turbulence intensity $\mathrm{Tu}$ in the shear flow region $\left(z / Z_{90}<0 \cdot 5\right)$. The interfacial turbulence intensity increased from about zero to more than $200 \%$ with increasing elevation across the shear flow. The large interfacial velocity fluctuation corresponded to the formation and convection of large vortical structures with alternate positive and negative instantaneous velocities. Smaller turbulence intensity was observed for the smallest Reynolds number, consistent with the findings of Wang and Chanson (2016).

The turbulent velocity in the tidal bore was measured at a fixed longitudinal location ( $x=8.5 \mathrm{~m}$ from the upstream end) and a number of vertical elevations, beneath the initial water level. Typical ensemble-averaged velocity characteristics are presented in Figure 14. Time variations of the ensemble-averaged velocity highlighted a marked deceleration of the longitudinal velocity $V_{x}$ associated with bore propagation. In breaking bores with Froude numbers $>1 \cdot 5$, recirculation velocities were observed at the end of the deceleration phase, characterised by a negative longitudinal velocity. At the same time, the vertical velocity $V_{z}$ showed a marked acceleration followed by an immediate deceleration, which was more pronounced at higher vertical elevations. The transverse velocity $V_{y}$ showed some large fluctuations with the bore passage, indicating that the propagation of tidal bores is a three-dimensional process. The findings were consistent with field observations (Toi and Chanson 2013).

The velocity fluctuations, quantified as $\left(V_{75}-V_{25}\right)$ were associated with some marked increase in all directions at all elevations during and after the bore propagation. The magnitudes of fluctuations were larger at lower vertical elevations compared with close to the initial water surface, and with the vertical velocity component compared with other two velocity components for the same flow condition. The maximum velocity fluctuations $\left(V_{x, 75}-V_{x, 25}\right)_{\max },\left(V_{y, 75}-V_{y, 25}\right)_{\max }$ and $\left(V_{z, 75}-V_{z, 25}\right)_{\max }$ all occurred at a time lag $\Delta t_{\mathrm{V}}$ compared with the initiation of longitudinal deceleration. The relationships between the maximum velocity fluctuation, the associated time lag and vertical location beneath the water were analysed. The time lag $\Delta t_{\mathrm{V}}$ was calculated as the time difference between the occurrence of the maximum fluctuation and the arrival of the bore front, defined as the initiation of the free-surface rise. (Mathematically, this would be equal to the inception of the depth derivative being non-zero.) Typical results are presented in Figure 15. Figure 15 shows the maximum velocity fluctuations and the associated time lag at different vertical elevations for $\mathrm{Fr}_{1}=1.5$ and two Reynolds numbers. The results highlighted higher maximum fluctuations in the vertical velocity component, especially for the highest vertical elevation. The magnitudes of maximum fluctuations increased with increasing vertical elevations, for all velocity components except for the longitudinal velocity. With the longitudinal 


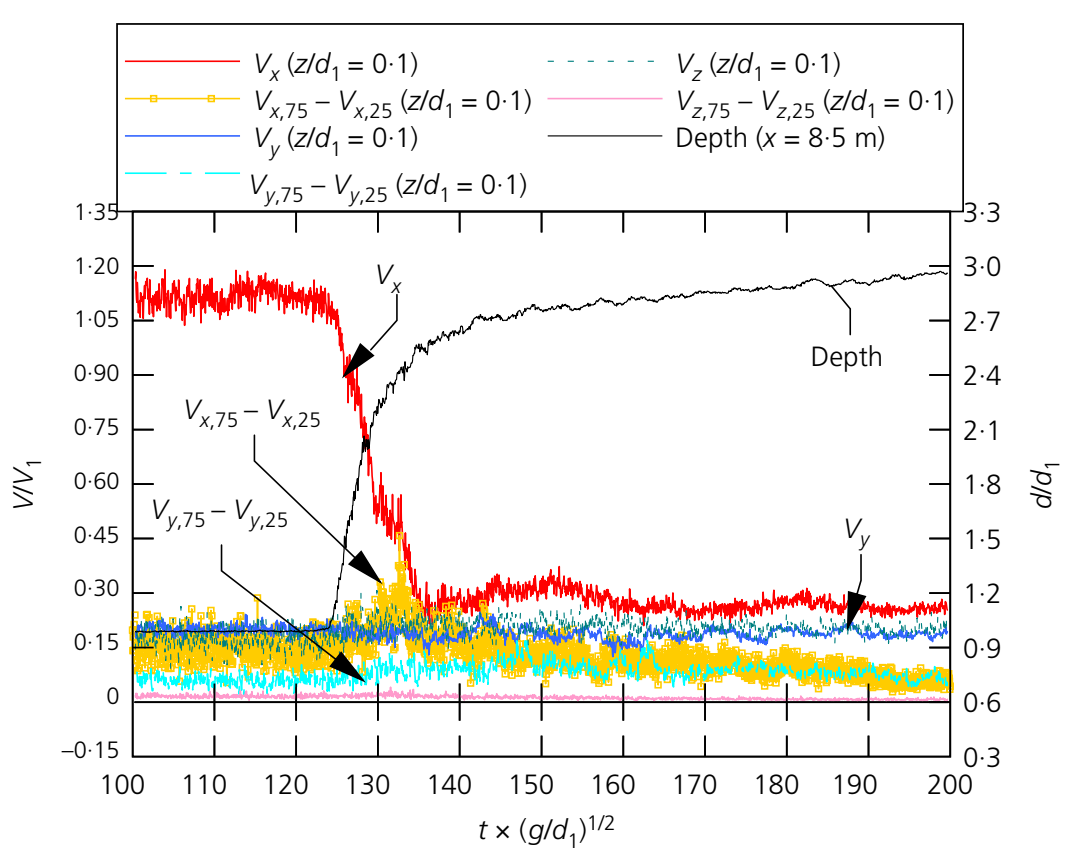

(a)

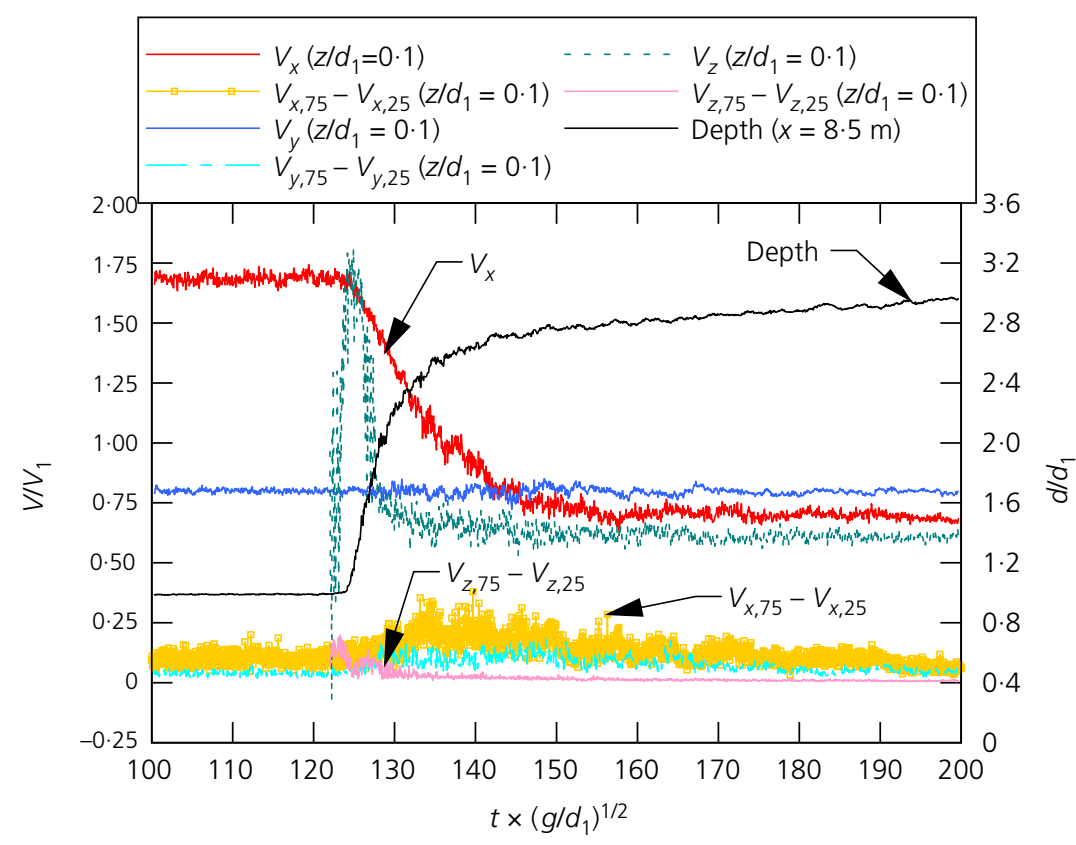

(b)

Figure 14. Time variations of the ensemble-averaged velocity at different vertical elevations of breaking bore with $\mathrm{Fr}_{1}=2 \cdot 1$ :

(a) $z / d_{1}=0.1 ;$ (b) $z / d_{1}=0.8$

velocity, the maximum fluctuations occurred at the lowest elevation, close to the channel bed. The time lag showed a broad scatter, with the upper water column having the largest scatter of time lag (Figure 15). All velocity components were associated with longer time lag as the vertical elevation increased. Further, the data showed consistently larger time lag 


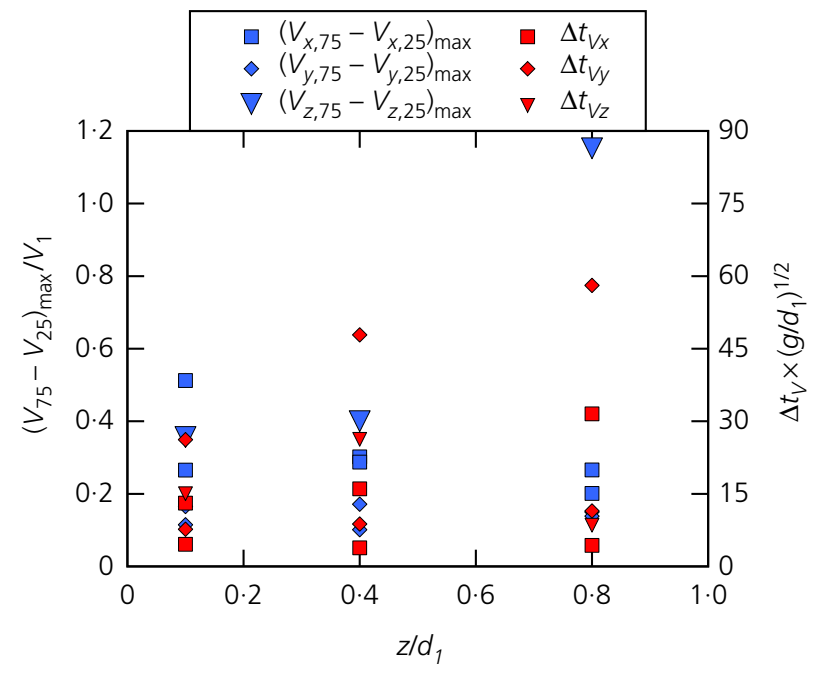

Figure 15. Maximum velocity fluctuations in breaking bore and the associated time lag measured at different vertical elevations $\mathrm{Fr}_{1}=1.9, \mathrm{Re}=9 \times 10^{4}$ and $3 \times 10^{5}$

for the maximum transverse velocity fluctuation compared with the other two velocity components.

\section{Conclusion}

Bores, compression waves and hydraulic jumps are very rapidly varied free-surface flows. Geophysical applications range from tidal bores and in-river tsunamis, including swash zones and riverine systems, while man-made applications encompass energy dissipators at spillway toe, positive surges in hydropower canals, bathtubs and kitchen sinks. Breaking bores and surges are characterised by a highly turbulent flow region, called the roller, in which large amounts of turbulent kinetic energy are dissipated, while air bubbles and packets are entrained through the roller surface and at the roller toe. In stationary hydraulic jumps and breaking bores, the flow structure in the roller region remains a great challenge to study, due to bubble-turbulence interactions and the interplay between turbulent properties, free-surface deformations and large quantities of entrained air. A key feature of breaking jumps and bores is the large and rapid spatial and temporal deformations of the roller, coupled with the interactions between entrained air and turbulent vortices. On the basis of detailed physical modelling in relatively large-size facilities, the state of the art is discussed in terms of the free-surface profiles, void fraction and velocity distributions under breaking bores and hydraulic jumps.

Breaking bores and hydraulic jumps with a marked roller present a number of similar features. Recent findings demonstrated that the roller is a highly unsteady turbulent region, with both the roller toe and free surface constantly fluctuating with time and space, albeit the roller shape is quasi-two-dimensional on average. The roller toe constitutes a hydrodynamic singularity that is a line source of both entrained air and vorticity. Downstream of the roller toe, air bubbles and vorticity are diffused in the mixing zone at different rates, with strong interactions between entrained bubbles and turbulent structures. This double diffusive convection process leads to a complex interplay between instantaneous free-surface deformations, velocity fluctuations, interfacial processes including breakup and coalescence and dissipative processes.

\section{Acknowledgements}

The authors acknowledge Professor Peter Davies, Editor, for his encouragements and advice. The financial support of the Australian Research Council (grant DP120100481) and of the University of Queensland's School of Civil Engineering is acknowledged.

\section{REFERENCES}

Bakhmeteff BA (1932) Hydraulics of Open Channels, 1st edn. McGraw-Hill, New York, NY, USA.

Bélanger JB (1841) Notes sur l'Hydraulique. Ecole Royale des Ponts et Chaussées, Paris, France, session 1841-1842 (in French).

Bidone G (1819) Le Remou et sur la Propagation des Ondes. Report to Académie Royale des Sciences de Turin, Turin, séance, vol. XXV, pp. 21-112 and 4 plates (in French).

Brocchini M and Peregrine DH (2001a) The dynamics of strong turbulence at free surfaces. Part 1. Description. Journal of Fluid Mechanics 449: 225-254.

Brocchini M and Peregrine DH (2001b) The dynamics of strong turbulence at free surfaces. Part 2. Free-surface boundary conditions. Journal of Fluid Mechanics 449: 255-290.

Carvalho RF, Lemos CM and Ramos CM (2008) Numerical computation of the flow in hydraulic jump stilling basins. Journal of Hydraulic Research, IAHR 46(6): 739-775.

Chachereau $Y$ and Chanson H (2011) Free-surface fluctuations and turbulence in hydraulic jumps. Experimental Thermal and Fluid Science 35(6): 896-909.

Chanson H (2009a) Turbulent air-water flows in hydraulic structures: dynamic similarity and scale effects. Environmental Fluid Mechanics 9(2): 125-142.

Chanson H (2009b) Current knowledge in hydraulic jumps and related phenomena. A survey of experimental results. European Journal of Mechanics B/Fluids 28(2): 191-210.

Chanson H (2011) Tidal Bores, Aegir, Eagre, Mascaret, Pororoca: Theory and Observations. World Scientific, Singapore. 
Chanson H (2012) Momentum considerations in hydraulic jumps and bores. Journal of Irrigation and Drainage Engineering, ASCE 138(4): 382-385.

Chanson H and Brattberg T (2000) Experimental study of the air-water shear flow in a hydraulic jump. International Journal of Multiphase Flow 26(4): 583-607.

Chanson H and Carvalho R (2015) Hydraulic jumps and stilling basins. In Energy Dissipation in Hydraulic Structures (Chanson H (ed.)). CRC Press, Taylor \& Francis Group, Leiden, the Netherlands, pp. 65-104.

Chanson H and Gualtieri C (2008) Similitude and scale effects of air entrainment in hydraulic jumps. Journal of Hydraulic Research, IAHR 46(1): 35-44.

Chanson $\mathrm{H}$ and Toombes L (2002) Air-water flows down stepped chutes: turbulence and flow structure observations. International Journal of Multiphase Flow 28(11): 1737-1761.

Favre H (1935) Etude Théorique et Expérimentale des Ondes de Translation dans les Canaux Découverts. Dunod, Paris, France (in French).

Gonzalez A and Bombardelli FA (2005) Two-phase-flow theoretical and numerical models for hydraulic jumps, including air entrainment. In Proceedings of the 31st IAHR Congress, Seoul, 2005: Water Engineering for the Future, Choices and Challenges (Jun BH, Lee SI, Seo IW and Choi GW (eds)). Korea Water Resources Association, Seoul, Republic of Korea (CD-ROM).

Hager WH (1992) Energy Dissipators and Hydraulic Jump. Kluwer, Dordrecht, the Netherlands.

Henderson FM (1966) Open Channel Flow. MacMillan Company, New York, NY, USA.

Jaeger C (1956) Engineering Fluid Mechanics. Blackie \& Son, Glasgow, UK.

Kobus H (ed.) (1984) Symposium on Scale Effects in Modelling Hydraulic Structures. Institut für Wasserbau, Universität Stuttgart, Stuttgart, Federal Republic of Germany. Leng $X$ and Chanson H (2015a) Breaking bore: physical observations of roller characteristics. Mechanics Research Communications 65: 24-29.

Leng $X$ and Chanson H (2015b) Turbulent advances of a breaking bore: preliminary physical experiments. Experimental Thermal and Fluid Science 62: 70-77.

Leng $X$ and Chanson $H$ (2016) Coupling between free-surface fluctuations, velocity fluctuations and turbulent Reynolds stresses during the upstream propagation of positive surges, bores and compression waves. Environmental Fluid Mechanics 16(4): 695-719 and digital appendix.

Liggett JA (1994) Fluid Mechanics. McGraw-Hill, New York, NY, USA.

Lighthill J (1978) Waves in Fluids. Cambridge University Press, Cambridge, UK.

Lubin P and Glockner S (2015) Numerical simulations of three-dimensional plunging breaking waves: generation and evolution of aerated vortex filaments. Journal of Fluid Mechanics 767: 364-393.

Lubin P, Glockner S and Chanson H (2009) Numerical simulation of air entrainment and turbulence in a hydraulic jump. Proceedings of Colloque SHF Modèles Physiques Hydrauliques: Outils Indispensables du XXIe Siècle?, Société Hydrotechnique de France, Lyon, France, pp. 109-114.

Lubin P, Chanson H and Glockner S (2010) Large eddy simulation of turbulence generated by a weak breaking tidal bore. Environmental Fluid Mechanics 10(5): 587-602.

Ma J, Oberai AA, Lahey RT Jr and Drew DA (2011) Modeling air entrainment and transport in a hydraulic jump using two-fluid RANS and DES turbulence models. Heat and Mass Transfer 47(8): 911-919.

Mortazavi M, Le Chenadec V, Moin P and Mani A (2016) Direct numerical simulation of a turbulent hydraulic jump: turbulence statistics and air entrainment. Journal of Fluid Mechanics 797: 60-94.

Mouaze D, Murzyn F and Chaplin JR (2005) Free surface length scale estimation in hydraulic jumps. Journal of Fluids Engineering, Transactions of the ASME 127(6): 1191-1193.

Murzyn F and Chanson H (2008) Experimental assessment of scale effects affecting two-phase flow properties in hydraulic jumps. Experiments in Fluids 45(3): 513-521.

Murzyn F and Chanson H (2009) Free-surface fluctuations in hydraulic jumps: experimental observations. Experimental Thermal and Fluid Science 33(7): 1055-1064.

Murzyn F, Mouaze D and Chapling JR (2005) Optical fibre probe measurements of bubbly flow in hydraulic jumps. International Journal of Multiphase Flow 31(1): $141-154$.

Murzyn F, Mouaze D and Chaplin JR (2007) Air-water interface dynamic and free surface features in hydraulic jumps. Journal of Hydraulic Research, IAHR 45(5): 679-685.

Novak P and Cabelka J (1981) Models in Hydraulic Engineering. Physical Principles and Design Applications. Pitman Publishing, London, UK.

Richard GL and Gavrilyuk SL (2013) The classical hydraulic jump in a model of shear shallow-water flows. Journal of Fluid Mechanics 725: 492-521.

Rizzi A and Vos J (1998) Toward establishing credibility in computational fluid dynamics simulations. AIAA Journal 36(5): 668-675.

Roache RL (1998) Verification of codes and calculations. AIAA Journal 36(5): 696-702.

Roache PJ (2009) Perspective: validation - what does it mean? Journal of Fluids Engineering, ASME 131(3): 034503-034503-4.

Spiegel MR (1974) Mathematical Handbook of Formulas and Tables. McGraw-Hill Inc., New York, NY, USA. 
Stoker JJ (1957) Water waves. In The Mathematical Theory with Applications. Interscience Publishers, New York, NY, USA.

Toi YH and Chanson H (2013) Turbulent mixing in breaking tidal bores: comparison between field and laboratory data. In Proceedings of 35th IAHR World Congress, Chengdu, China (Wang Z, Lee JHW, Gao J and Cao S (eds)). IAHR, Beijing, China, Paper A10201.

Tricker RAR (1965) Bores, Breakers, Waves and Wakes. American Elsevier Publ. Co., New York, NY, USA.

Wang $\mathrm{H}$ and Chanson $\mathrm{H}$ (2015a) Air entrainment and turbulent fluctuations in hydraulic jumps. Urban Water Journal 12(6): 502-518.

Wang $\mathrm{H}$ and Chanson $\mathrm{H}$ (2015b) Experimental study of turbulent fluctuations in hydraulic jumps. Journal of Hydraulic Engineering, ASCE 141(7): 04015010-1-04015010-10.

Wang $\mathrm{H}$ and Chanson H (2016) Self-similarity and scale effects in physical modelling of hydraulic jump roller dynamics, air entrainment and turbulent scales. Environmental Fluid Mechanics 16(6): 1087-1110.

Wang $\mathrm{H}$ and Murzyn F (2016) Experimental assessment of characteristic turbulent scales in two-phase flow of hydraulic jump: from bottom to free surface. Environmental Fluid Mechanics, http://dx.doi.org/10.1007/s10652-0169451-6.

Wang H, Felder S and Chanson H (2014) An experimental study of turbulent two-phase flow in hydraulic jumps and application of a triple decomposition technique. Experiments in Fluids 55(7): Paper 1775.

Wood IR (ed.) (1991) Air Entrainment in Free-Surface Flows: IAHR Hydraulic Structures Design Manuals 4. Balkema, Rotterdam, the Netherlands.

Zhang G, Wang H and Chanson H (2013) Turbulence and aeration in hydraulic jumps: free-surface fluctuation and integral turbulent scale measurements. Environmental Fluid Mechanics 13(2): 189-204.

\section{HOW CAN YOU CONTRIBUTE?}

To discuss this paper, please email up to 500 words to the editor at journals@ice.org.uk. Your contribution will be forwarded to the author(s) for a reply and, if considered appropriate by the editorial board, it will be published as discussion in a future issue of the journal.

Proceedings journals rely entirely on contributions from the civil engineering profession (and allied disciplines). Information about how to submit your paper online is available at www.icevirtuallibrary.com/page/authors, where you will also find detailed author guidelines. 